\title{
Abnormal function of telomere protein TRF2 induces cell mutation and the effects of environmental tumor-promoting factors (Review)
}

\author{
ZHENGYI WANG ${ }^{1-3}$ and XIAOYING WU \\ ${ }^{1}$ Good Clinical Practice Center, Sichuan Academy of Medical Sciences and Sichuan Provincial People's Hospital, \\ Chengdu, Sichuan 610071; ${ }^{2}$ Institute of Laboratory Animals of Sichuan Academy of Medical Sciences and \\ Sichuan Provincial People's Hospital; ${ }^{3}$ Yinglongwan Laboratory Animal Research Institute, \\ Zhonghe Community, High-Tech Zone, Chengdu, Sichuan 610212; ${ }^{4}$ Ministry of Education and Training, \\ Chengdu Second People's Hospital, Chengdu, Sichuan 610000, P.R. China
}

Received March 24, 2021; Accepted June 14, 2021

DOI: 10.3892/or.2021.8135

\begin{abstract}
Recent studies have found that somatic gene mutations and environmental tumor-promoting factors are both indispensable for tumor formation. Telomeric repeat-binding factor (TRF) 2 is the core component of the telomere shelterin complex, which plays an important role in chromosome stability and the maintenance of normal cell physiological states. In recent years, TRF2 and its role in tumor formation have gradually become a research hot topic, which has promoted in-depth discussions into tumorigenesis and treatment strategies, and has achieved promising results. Some cells bypass elimination, due to either aging, apoptosis via mutations or abnormal prolongation of the mitotic cycle, and enter the telomere crisis period, where large-scale DNA reorganization occurs repeatedly, which manifests as the precancerous cell cycle. Finally, at the end of the crisis cycle, the mutation activates either the expression level of telomerase or activates the alternative lengthening of telomere mechanism to extend the local telomeres. Under the protection of TRF2, chromosomes are gradually stabilized, immortal cells are formed and the stagewise mutation-driven transformation of normal cells to cancer cells is completed. In addition, TRF2 also shares the characteristics of environmental tumor-promoting factors. It acts on multiple signal transduction pathway-related proteins associated with cell proliferation, and affects peripheral angiogenesis, inhibits the immune recognition and killing ability of the
\end{abstract}

Correspondence to: Professor Zhengyi Wang, Yinglongwan Laboratory Animal Research Institute, Zhonghe Community, High-Tech Zone, 10 QingYunnan Street, Chengdu, Sichuan 610212, P.R. China

E-mail: 983927965@qq.com

Key words: telomere, TRF2, tumor formation, clinical tumor therapy target microenvironment, and maintains the stemness characteristics of tumor cells. TRF2 levels are abnormally elevated by a variety of tumor control proteins, which are more conducive to the protection of telomeres and the survival of tumor cells. In brief, the various regulatory mechanisms which tumor cells rely on to survive are organically integrated around TRF2, forming a regulatory network, which is conducive to the optimization of the survival direction of heterogeneous tumor cells, and promotes their survival and adaptability. In terms of clinical application, TRF2 is expected to become a new type of cancer prognostic marker and a new tumor treatment target. Inhibition of TRF2 overexpression could effectively cut off the core network regulating tumor cell survival, reduce drug resistance, or bypass the mutation under the pressure of tumor treatment selection, which may represent a promising therapeutic strategy for the complete eradication of tumors in the clinical setting. Based on recent research, the aim of the present review was to systematically elaborate on the basic structure and functional characteristics of TRF2 and its role in tumor formation, and to analyze the findings indicating that TRF2 deficiency or overexpression could cause severe damage to telomere function and telomere shortening, and induce DNA damage response and chromosomal instability.

\section{Contents}

\section{Introduction}

2. TRF2 structure and function maintenance

3. Functional characteristics of TRF2 and the maintenance of cell chromosome stability

4. Association of TRF2 dysfunction with CIN and tumor formation

5. TRF2 and tumor angiogenesis

6. TRF2 and tumor signal transduction pathways

7. TRF2 and CSCs

8. TRF2 and tumor immunity

9. Targeting TRF2 and tumor therapy

10. Conclusion 


\section{Introduction}

It is well-known that cancer driver genes play an important role in the occurrence and development of tumors. Gene mutations continuously accumulate with aging or in tumor lesions. However, previous studies have found that there are also numerous somatic mutations in normal adult tissues, as well as specific 'cancer-driven mutations', for example, mutations in the cancer-driving gene Notch1 $(1,2)$. Therefore, there is a view that the main risk factor for cancer development is not persistent carcinogenic mutations, but the exposure of the initial mutant cells to an environment that promotes tumor development $(3,4)$. This is consistent with the decisive role of the tumor microenvironment in the process of tumor formation and development. Data analysis found that the telomeric repeat-binding factor (TRF)2 protein was dysfunctional, possessing the dual characteristics of promoting cell mutation and the formation of extracellular tumor-promoting environment factors, and plays a key role in the process of tumor formation (5-8).

Telomeres are a type of DNA-protein complex structure, which seal the ends of the chromosome arms of eukaryotic cells and maintain the stability of the genome. Telomeres are essential for the integrity of the chromosomes. In all mammals, telomeres are composed of a highly conserved hexamer (TTAGGG) tandem repeating DNA sequence and telomere binding protein, which is composed of the shelterin complex, accessory factors and telomerase $(5,9,10)$. The shelterin complex can specifically bind to telomere DNA to cause the telomere end structure to form a telomere loop (T-loop), assisting the telomeres to form caps and protecting the ends of chromosomes from DNA double-strand break (DSB) recognition, thereby inhibiting DNA damage response (DDR), maintaining the integrity of telomere structure and function, and preserving chromosome stability (9). Human shelterin complexes consist of six core proteins: TRF1 and TRF2, TERF1-interacting nuclear factor 2 (TINF2), TRF2-interacting protein 1 (also known as repressor/activator protein 1; RAP1), protection of telomeres 1 (POT1) and POT1-binding protein 1 (also known as telomere-binding protein POT1-interacting protein 1; TPP1) and a tripeptide kinase (10). The shelterin proteins, TRF1 and TRF2, display specific affinity for the double-stranded (ds) DNA of the telomere, while the POT1-TPP1 shelterin subcomplex covers single-stranded telomere G-rich overhangs (11). Based on the currently available-related research, the present review aimed to systematically discuss the basic structure and functional characteristics of TRF2, and elucidate its role in tumor formation.

\section{TRF2 structure and function maintenance}

TRF2 is an important polypeptide in the telomere shelterin complex. The gene is located on chromosome $16 \mathrm{q} 22.1,30 \mathrm{~kb}$ in length and is widely expressed in numerous tissues in humans (National Centre Biotechnology Information via flatfile form; ftp://ftp.ncbi. nih.gov/genomes/). TRF2 includes 4 functional domains, which are described as follows: i) The N-terminal basic region [glycine and arginine-rich (GAR) or basic domain], which is rich in glycine and arginine residues, and is indispensable for the basic protective function of TRF2 (9). Knocking down expression of non-coding telomere repeats-containing RNA (TERRA) using short inhibiting RNA lead to telomere dysfunction, including increased metaphase chromosomal aberrations (an 1.4-fold increase in telomere repeat signal intensity, but no significant change in average telomere length) and telomere lesions associated with p53-binding protein 1 (53BP1) and phosphorylated histone $\operatorname{H2AX}(\gamma-\mathrm{H} 2 \mathrm{AX})(9,12)$. The TRF2 basic domain can recruit and bind TERRA independent of the telomere sequence, and it can interact with subunits of the origin recognition complex 1 domain associated with the TRF2 basic domain to promote telomere heterochromatin formation and participate in the regulation of DDR (12). The complete basic domain, via non-specific electrostatic attraction, notably enhances the affinity of TRF2 to DNA and protects the telomere displacement loop (D-loop) from cleavage by endonucleases (13). ii) The dimerization domain, also known as the TRF homology (TRFH) domain, is involved in the formation of homodimers. Similar to TRF1, it has the same $\alpha$ helix structure, resembling a twisted horseshoe (5). The dimerization interface exhibits unique interactions, which can prevent heterodimerization (5). TRFH is a protein domain that can recognize specific peptides of the (Y/F)XL motif, and it is also a hub structure of multiple (Y/F)XL motif-containing protein signals, which mediate telomere length control and end protection. For example, the TRF2-TINF2 interaction regulates telomere formation and activation of telomerase (a specialized DNA polymerase which adds repeats of telomere DNA to the ends of chromosomes) $(14,15)$. In addition, the TRF2-Apollo and TRF2-microcephalin interactions regulate DNA damage repair response $(16,17)$ and play an important role in molecular dimerization, DNA binding and telomere positioning (18). In the TRFH domain of TRF2, lysine and arginine residues are surrounded by $90 \mathrm{bp}$ DNA. This structure is important in maintaining the topological structure of telomere DNA, inhibiting the activation of the ataxia telangiectasia-mutated (ATM) kinase checkpoint and preventing telomere non-homologous end joining (NHEJ) (19). iii) The orientation sequence (nuclear localization signal), or flexible hinge domain, contains TRF2 and other shelterin proteins, such as RAP1 and TINF2 interaction sites $(11,20)$. iv) The C-terminal domain [Myb/homeodomain-like telobox DNA-binding domain (DBD)] is mainly responsible for the specific recognition and binding of the telobox DNA repeat sequence, TTAGGG $(14,21)$. TRF2 DBD binds to telomere DNA and nuclear chromosome arrays, and rarely non-specifically binds to non-telomere DNA sequences (22).

Telomeres functionally maintain the stability of chromosomes and the biological clock-like function of DNA replication, and their stability depends on 2 mechanisms. The first relies on telomerase or alternative lengthening of telomere (ALT) activity, which can compensate for replication erosion; the second relies on its own special chromatin organization, which protects the ends of chromosomes from abnormal signals and repair $(9,11)$. Chromatin-mediated telomere protection involves several protein-regulated pathways, which directly or indirectly bind to telomere DNA, such as the shelterin complex $(23,24)$. The TRF2 protein in the shelterin complex is important for maintaining the normal functional state of telomeres and is considered as a telomere protective protein. For example, TRF2 folds human telomeres into loops 


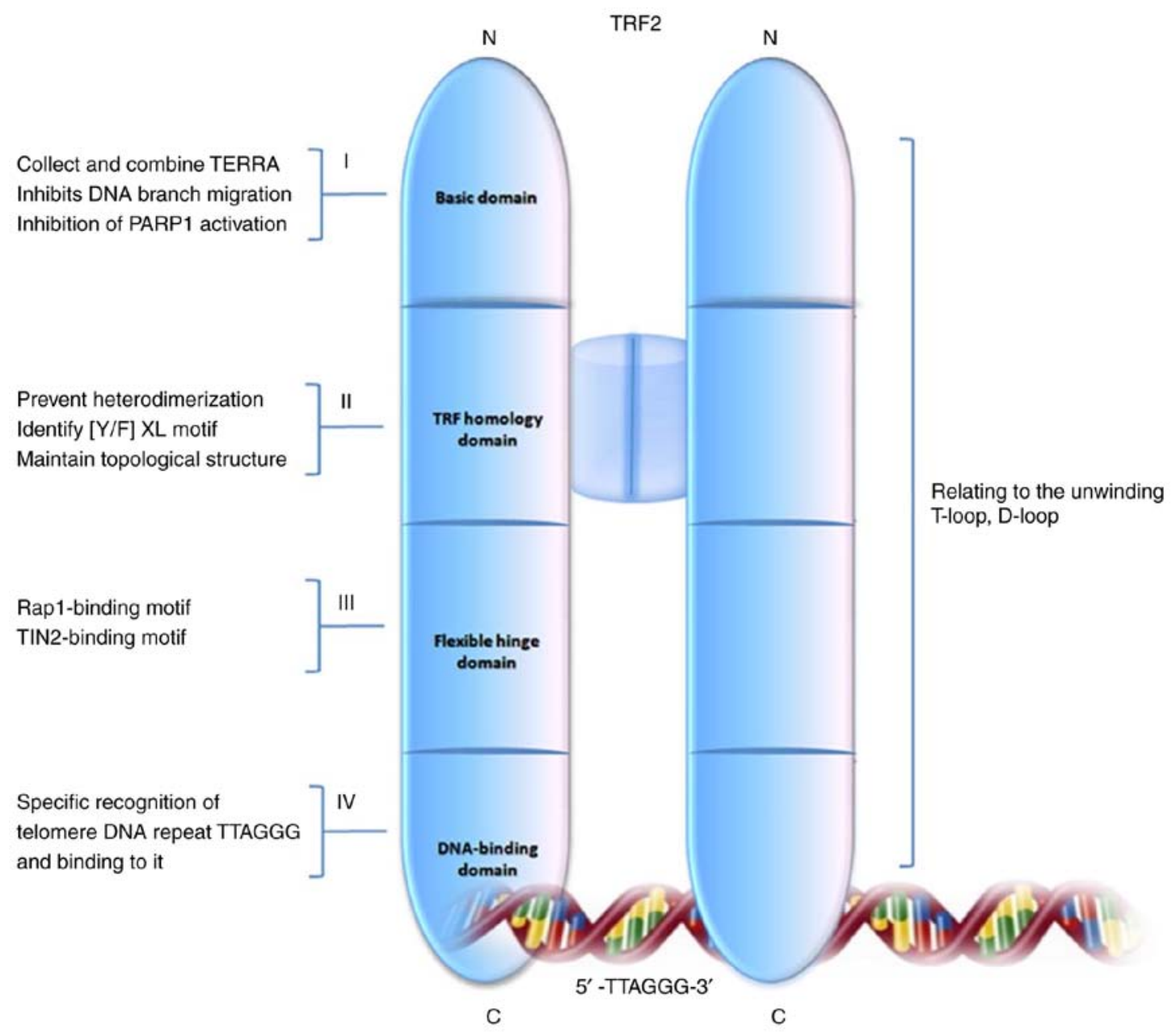

Figure 1. Schematic diagram of TRF2 structure and its main functions. TRF2 includes 4 functional domains: Basic, TRF homology, flexible hinge and DNA-binding domains. Different structural domains have functional characteristics of I, II, III and IV, respectively. The various structural domains of TRF2 act synergistically and play an important role in regulating the orderly assembly and untwisting of the T- and D-loops. The structural variation of TRF2 can cause large fragments of telomeres to be lost, resulting in severe telomere shortening. TRF2, telomeric repeat-binding factor 2; T-loop, telomere loop; D-loop, telomere displacement loop; C, C-terminal; N, N-terminal; TERRA, telomeric repeat-containing RNA; RAP1, repressor/activator protein 1; TINF2, TERF1-interacting nuclear factor 2.

to prevent unnecessary DDR, blocks ATM signaling and NHEJ, and promotes telomere replication, serving as a key regulator of telomere integrity $(9,24-26)$. The structure and main functions of TRF2 are shown in Fig. 1.

\section{Functional characteristics of TRF2 and the maintenance of cell chromosome stability}

TRF2 maintains and dynamically regulates the structure of eukaryotic telomere end loops. TRF2 protein mutation or abnormal expression (particularly domain mutation associated with loop assembly, including the basic and the RBM domains) leads to loss of the T-loop, loss of protection of the DNA end, DDR or end-to-end fusion, chromosomal instability (CIN), cell aging, apoptosis or malignant transformation. With respect to morphology, the linear chromosomes of eukaryotes end with nuclear protein complex telomeres. Mammalian telomere DNA is composed of several kbp 5'-TTAGGG-3' repeats and the ends are terminated in a 50-400 nucleotide single-stranded overhang, with a G-rich sequence. The dsDNA of telomere repeats forms a T-loop and the 3 ' end of the single strand of the telomere is inserted into the dsDNA of the telomere (i.e., the
3' overhang end is paired with the C-rich strand). The G-rich strand, in the double strand, is replaced to form a replacement loop, which is called D-loop. This telomere ring structure hides the ends of the chromosomes to protect the stability of telomere DNA from DDR or end-to-end fusion (27).

With respect to biological function, TRF2 mediates the formation of loop structures. The functional elimination of TRF2 in the cell will result in the loss of the loop structure (28). In the absence of other shelterin proteins, TRF 2 can also form a T-loop alone (29), mediating telomere protection at different cell cycle stages (30). The mechanism of T-loop formation is associated with the ability of TRFH domains in TRF2 to bind DNA with low affinity and change the DNA topology (19). It has been found that the TRF2 dimer, via several lysine and arginine residues located around TRFH, encapsulates $\sim 90 \mathrm{bp}$ DNA and forms DNA topology. For TRF2 mutants with insufficient encapsulates (named Top-less), the topological structure of telomere DNA can be changed and the number of terminal T-loops can be reduced (19). This encapsulation also only occurs when the Myb/SANT domain of TRF2 and the dsDNA TTAGGG repeat sequence are bound to each other (19). 
The formation and/or maintenance of the T-loop does not require the $\mathrm{N}$-terminal basic domain of TRF2, but this domain can bind to and cover the branched-DNA 3-way junction. The 3-way junction structure contains the poly(ADP-ribose) polymerase (PARP)1 activation site, and the activation of PARP1 can cause the harmful poly(ADP-ribosyl)ation (PARsylation) of the telomere protein (31). The TRF2 protein basic domain, H31A and the TINF2 protein jointly inhibit PARP1 activity, and inhibit the migration of branched-DNA to form double Holliday junction $(\mathrm{dHJ})$, stabilize the T-loop, prevent it from being cut and thereby prevent telomere shortening (31). Therefore, the basic domain of TRF2 is crucial for the stability of the T-loop.

In the cell cycle, the T-loop is a highly dynamic and regulated structure, and its assembly and disassembly are coordinated in the cell cycle. The T-loop requires twining and unfolding in an orderly and alternate manner, controlling the protection and replication functions of the DNA ends, and coordinating the structural contradiction between the two functions (32). A previous study found that there was a cyclin-dependent kinase (CDK)2 phosphorylation site at Ser365 of TRF2, which was shown to be phosphorylated in the $G_{1}, G_{2}$ and $M$ phases, but not in the $S$ phase (32). Due to the dephosphorylation of the phosphatase, PP6R3, which is enriched in the $\mathrm{S}$ phase, a narrow window is created at Ser365. The helicase regulator of telomere elongation helicase 1 (RTEL1) can enter and untie the T-loop instantaneously, relieving the collision between the S-phase replication fork and the T-loop, and promote telomere DNA replication. At the Ser365 site of TRF2 in cell cycle phases, other than the $\mathrm{S}$ phase, RTEL1 is repelled and released from telomeres, and TRF2 is again phosphorylated, restoring the T-loop structure. This not only prevents the disorderly unwrapping of the T-loop and inappropriate activation of ATM, but also counteracts the replication conflicts of the secondary DNA structure in the telomere and the genome. Therefore, the phosphorylation switch in TRF2 coordinates the assembly and disassembly of the T-loop during the cell cycle, protecting telomeres from replication stress and unplanned DDRs (32).

In-depth studies have found that the interaction site of RTEL1 with TRF2 is mapped to an uncharacterized C4C4 metal-binding motif (33). The p.R1264H mutation in the C4C4 motif can disrupt the S-phase RTEL1-TRF2 interaction and leads to a T-loop split, accompanied by rapid changes in telomere length, telomere loss and T-circle (TC) formation. The amino acid p.I124D mutation, in the TRFH dimerization domain of TRF2, can also specifically disrupt the binding to RTEL1 and prevent its recruitment on telomeres, thereby phenotypically replicating the p.R1264H mutation in RTEL1, leading to T-loop abnormal resection, uneven telomere length, telomere loss and TC formation (33). Therefore, TRF2 plays an important role in coordinating T-loop assembly and disassembly during the cell cycle.

In addition to the T-loop, the D-loop must also be disassembled immediately during DNA replication. An in vitro purified protein function test found that TRF2 exerted a notable inhibitory effect on single-stranded (ss) DNA strand invasion and D-loop formation mediated by Rad51 in the telomere template, which is not conducive to the formation of the D-loop structure; however, in the non-telomeric region of the genome or Myb domain mutants, it could promote single strand invasion and D-loop formation, and was conducive to homology recombination, which may be associated with the specific structure and function of the dsDNA-binding domain (Myb SANT) of TRF2 (34).

After the formation of the D-loop, TRF2 binds to DNA, the toughness of its basic domain decreases, and it becomes structural and rigid. It can also prevent telomere D-loop unwinding caused by a variety of DNA unwinding factors and ensure the stability of the T-loop (13). RAP1 is recruited to the telomere and binds to the RBM domain of TRF2 to form the RAP1-TRF2 complex, which can restore the toughness of the TRF2 basic domain, eliminate non-specific DNA and histone electrostatic affinity of the TRF2 N-terminal, inhibit its interaction with DNA and mediate chromatin loosening (13). At this time, despite the presence of TRF2, RAP1 can also promote D-loop unwinding with helicase, which is beneficial for telomere extension and chromosome end replication. It can be seen that the combination of RAP1 and TRF2 can inhibit the affinity of the TRF2 basic domain to telomere DNA and eliminate the D-loop structure (13). Based on the aforementioned mechanism, as the cell cycle changes, TRF2 dynamically adjusts the D-loop to alternately unwind and close the loop, which not only stabilizes telomeres, but also ensures the normal progression of the cell cycle.

In summary, the different modes of action and functional state of the telomere protein, with TRF2 as the core, determines the loading and unloading regulation of the $\mathrm{T}$ - and D-loops to maintain chromosome stability, and the cell cycle of normal cells.

\section{TRF2 inhibits telomere DDR and abnormal repair}

$T R F 2$ regulation of $D D R$. Telomere deprotection occurs in aging or damaged cells, which coincides with the natural erosion of the chromosome ends. When the telomere reaches a very short length, DDR is no longer under control. The metabolic activity continues; however, the cell will still enter an irreversible stagnation state (35). The mechanism is associated with the decrease of TRF 2 protein content and function. When the telomere is severely shortened, it will erode numerous TRF2-binding sites. Insufficient TRF2 recruitment will lead to the failure of telomere protection, loss of its inhibitory effect on ATM and ATM activation. Phosphorylated ATM can induce subsequent localization of DDR components. For example, $\gamma$-H2AX and 53BP1 are recruited to the ends of the chromosomes, leading to the formation of what is referred to as telomere dysfunction-induced foci (TIF), activating the DDR cascade and inducing telomere repair (36).

The inhibitory effect of TRF2 on ATM has been associated with the functions of its TRFH domain and hinge domain, in the following 2 forms: i) The TRFH domain of TRF2 promotes the formation of the T-loop structure, hiding the $3^{\prime}$ ssDNA at the end of the telomere, in the double-stranded structure, which does not produce an interaction between the MRN complex and the DNA end similar to the DSB sensor; thus, preventing MRN-dependent ATM activation (35-37). Since the maintenance of the T-loop structure is associated with the functional integrity of TRF2, TRF2 dysfunction can induce the loss of T-loop protection at the telomere ends and expose the DNA, which can trigger the initial steps in 
the DDR pathway, trigger the ATM cascade and produce DDR (19). ii) The inhibitory DDR response (IDDR) domain of TRF2 regulates the activity of downstream proteins in the ATM cascade. At the $\gamma$-H2AX-labeled telomere, TRF2 relies on the deubiquitinating enzyme, BRCC 3 , and the ubiquitin ligase, UBR5, via the 'IDDR motif' in its hinge domain to hinder the recruitment of E3 ubiquitin ligase, RNF168, and inhibit its activity (37). With respect to RNF168, the DNA damage signal cascade is interrupted to prevent the positioning of 53BP1, thereby preventing chromosome end-to-end fusion (37). The ability of TRF2 to prevent the activation of the DDR pathway can also be enhanced with other shelterin subunits. For example, TRF1 recruits TINF2, which is conducive to the effective combination of TRF2 and telomeres, and strengthens the telomere protection function of TRF2. TINF2, together with TRF1 and TRF2, improve the telomere positioning and function of TRF2 $(38,39)$. A previous study found that Top-less telomere TIF cells maintained a certain NHEJ inhibitory ability, indicating that there was another mechanism protecting the ends of telomeres from NHEJ (19). If the expression of the TRF2-interacting protein, RAP1, in the telomeres is eliminated at this time, the repressive ability of NHEJ will be reduced and end-to-end fusion will occur. It can be observed that, when topology-mediated telomere protection is compromised, the presence of RAP1 can also serve as a backup mechanism for preventing NHEJ (19).

TRF2 has an inhibitory effect on the DDR cascade. It is well-known that the DDR cascade, under the monitoring of cell cycle checkpoints, can block the cell cycle, facilitate the repair of damaged DNA and maintain chromosome stability (30). Cells that are difficult to repair due to severe damage are eliminated by initiating the apoptotic cascade, to avoid the proliferation of abnormal cells with unstable chromosomes due to telomere damage, which will cause tissue and organ dysfunction $(30,31)$. TRF2 can prevent abnormal DNA enzymatic excision and maintain the integrity of telomeres and chromosomes (31). However, under certain conditions, TRF2 also exerts a significant inhibitory effect on DDR, that damages or severely shortens telomeres, allowing cells to evade cycle checkpoint monitoring and repair. Chromosomally unstable cells grow and proliferate under the promoting effect of cyclin. Due to CIN, the mutant cells in the genome cannot be cleared in a timely manner and mutations accumulate, increasing the risk for the occurrence of tumors and other genetic diseases (such as xeroderma pigmentosum syndrome) $(32,33,35,40)$. The inhibitory effect of TRF2 on the DDR cascade following telomere injury is shown in Fig. 2.

Regulatory effect of TRF 2 on the abnormal repair of telomere ends. When cell chromosomes are severely shortened, due to replicative wear and tear, or other pathological factors (such as, abnormal expression of TRF2, XPF enzyme digestion or telomere replication excision), the end loses the protection of the shelterin complex protein and is recognized by the cell as broken DNA $(36,37)$. At this time, DDR is activated, which induces abnormal repair and the mutual combination of broken ends, forming multiple centromeric chromosomes, losing the ability of normal replication and division of cells, and finally being eliminated $(9,29,33,35)$. This process may also be considered as the physiological effect of the self-protecting mechanism of the body, by eliminating aging or mutated cells, to maintain the relative chromosome stability of living tissue and cells, and avoid the occurrence of tumors or other related diseases, such as Bloom's syndrome or Werner syndrome $(41,42)$. Similar to the DSB repair mechanism, telomere ends are usually repaired in three ways: Canonical NHEJ (C-NHEJ), alternative NHEJ (A-NHEJ) and homologous recombination repair (HDR). Among these, C-NHEJ is the most common repair method. After TRF2expression is suppressed, the telomere ends lose their protective structure. Under the induction of DDR, the circular nucleoprotein Ku70/80 heterodimer is loaded to the telomere ends to prevent free DNA from being decomposed by nuclease $(43,44)$. After the protein, Ku recruits DNA-dependent protein kinase catalytic subunits, it further recruits and phosphorylates several factors, such as DNA ligase (Lig) IV and XRCC4, and finally each protein contributes to the completion of telomere-telomere fusion $(30,43,44)$. It was previously demonstrated that the Ku70 N-terminal Ku70 55 region residues contributed to the $\mathrm{Ku}-\mathrm{Ku}$ association between telomeres to form heterotetramers and prepared DNA end-joining. TRF2 can also interact with $\mathrm{Ku}$ via the Ku70 55 domain (the functional area of TRF2 has not yet been determined), blocking Ku from connecting the 2 telomere ends to directly inhibit NHEJ at the telomeres (45). Therefore, TRF2 is considered as the main inhibitor of telomere C-NHEJ, which directly inhibits $\mathrm{C}$-NHEJ via the negative regulation of $\mathrm{Ku}(45)$. The inhibition of C-NHEJ by TRF2 is shown in Fig. 3. Fig. 3A shows that the damaged shortened telomere ends bind to the Ku70/80 protein, and via the mutual affinity of the Ku70 $5 \alpha$ domains, a Ku70/80 heterotetramer is formed, leading to chromosome end-to-end fusion. Fig. 3B shows that TRF2 directly binds to the $5 \alpha$ domain of Ku70 to prevent the formation of Ku70/80 heterotetramers and inhibit the recruitment to the telomere ends of DNA-PKcs, Lig4, XRCC4 and XLF making the ends unable to be effectively connected.

The normal telomere T-loop structure, mediated by TRF2, can also limit the loading of the Ku70/80 heterodimer at the telomere ends; therefore, the presence of TRF2 at the telomeres may be beneficial for eliminating C-NHEJ. As the telomere C-NHEJ fusion requires ATM kinase activation (24), the key component of the cascade is 53BP1. It was previously found that, in the absence of 53BP1, even without TRF2, telomere C-NHEJ is very rare (46). On the one hand, the accumulation of 53BP1 at the telomeres, by recruiting a series of 53BP1-dependent DDR factors, including RIF1 and related shieldin complexes, reduces the end DNA strand excision effect of multiple nucleases, and inhibits other methods of telomere end joining, such as DNA homologous recombination repair (47). On the other hand, 53BP1 can promote the dynamic movement of DNA damage sites in the nucleus. Unprotected telomeres and other sites of DNA damage become more mobile and move in a larger area of the nucleus. 53BP1-mediated mobility increases the chance of telomeres approaching another telomere, thereby facilitating telomere fusion (47). Furthermore, the presence of 53BP1 can also cause the aggregation of unprotected telomeres, which may also promote telomere fusion (48). As aforementioned, the regulation of 53BP1 by the IDDR domain of the TRF2 hinge region can effectively inhibit C-NHEJ-mediated terminal fusion; therefore, inhibition of C-NHEJ by TRF2 is more conducive 


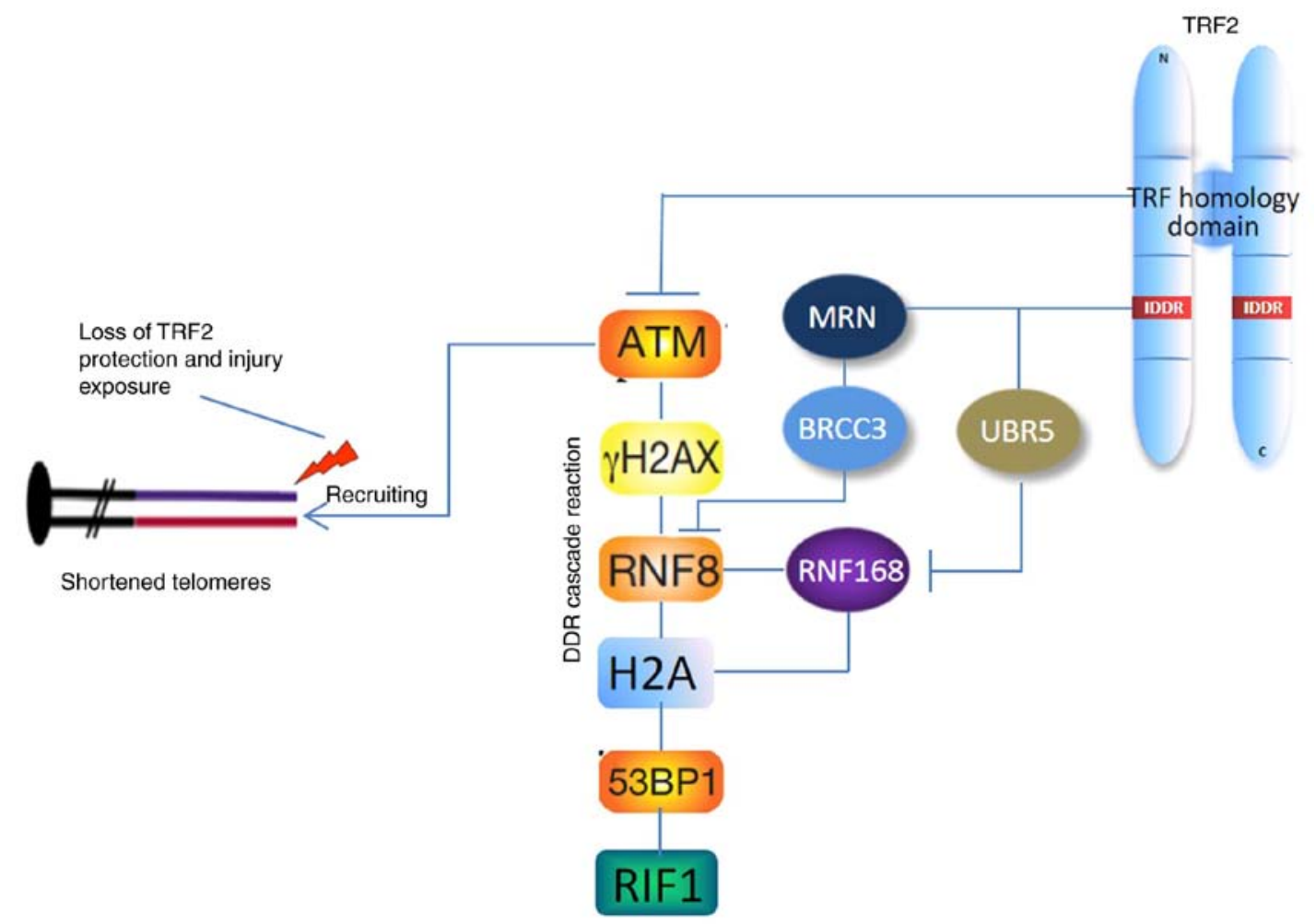

Figure 2. Schematic diagram of the inhibitory effect of TRF2 on the DDR cascade following telomere injury. The TRFH domain of TRF2 can directly inhibit ATM. The IDDR domain of the flexible hinge region can inhibit and degrade RNF8 and RNF168 via BRCC3 and UBR5, respectively, and arrest the DDR cascade at the RNF168 level. TRF2, telomeric repeat-binding factor 2; TRFH, TRF homology; DDR, DNA damage response; IDDR, inhibitory DDR response; ATM, ataxia telangiectasia mutated; $\gamma$-H2AX, phosphorylated H2AX; H2A, H2A histone; 53BP1, p53 binding protein 1; RIF1, replication timing regulatory factor 1; C, C-terminal; N, N-terminal.

to aging or abnormal cells bypassing the checkpoint block, promoting cell cycle progression and causing pathological mitosis, adversely affecting chromosome stability (49).

When cell telomeres lack $\mathrm{Ku}$ or Lig4 nucleoproteins, another alternative DSB repair mechanism is often used, referred to as A-NHEJ $(50,51)$. At the end of the telomere, PARP1 binds to the $5^{\prime}$ ds-ss transition site and is activated, thereby initiating A-NHEJ. The PARsylation of PARP1 to nearby proteins (including histones) creates a binding platform for DNA Lig3 and DNA polymerase. If the ends of 2 different DNAs have 3' overhangs and exhibit slight homology, DNA polymerase-mediated filling and Lig3 (or replication ligase Lig1) end ligation will result in A-NHEJ. The homology required for A-NHEJ is minimal ( $\geq 1$ base pairs) $(50,51)$. In the case of 2 dysfunctional telomeres, the homology between the $3^{\prime}$ overhang ends ( 2 bp per telomere repeat) is sufficient for A-NHEJ. $\mathrm{Ku} 70 / 80$ in C-NHEJ usually inhibits the A-NsHEJ pathway by competing with PARP1 at the end $(50,51)$. When shelterin is completely removed from the telomeres of cells lacking $\mathrm{Ku} 70 / 80$, almost all telomeres are fused by A-NHEJ (50). Another study found that, as TRF2 is an independent factor in the formation of the T-loop, it may hide the telomere ends in the T-loop to inhibit PARP1 activation, and A-NHEJ does not occur. However, knocking down the expression level of TRF2 with short inhibiting or shRNA from Ku70/80-deficient cells will only result in a mild telomere fusion phenotype (51). Mouse embryonic fibroblasts lacking TPP1 or POT1a/b can also exhibit low levels of A-NHEJ fusion (52), and TINF2 can also limit the accumulation of PARP1 in telomeres and inhibit the initiation of A-NHEJ (31), indicating that other shelterin components can synergistically enhance the inhibition of A-NHEJ. Therefore, mechanistically, T-loop formation and PARP1 blocking may be the 2 main mechanisms in which telomeres avoid this pathway. In addition, it was found that the Werner syndrome (WRN) protein exerts a regulatory effect on the induction of C-NHEJ and A-NHEJ. WRN promotes C-NHEJ via its helicase and nuclease functions, and prevents 5 ' end excision in a non-catalytic manner by inhibiting MRE11 and CTIP, thereby inhibiting A-NHEJ (53).

The physiological significance of cell replicative senescence is the inhibition of tumor formation. In critical short telomeres lacking telomerase, the HDR between sister chromatids can partially compensate for the loss of telomere repeats when telomerase is missing, thereby promoting early onset of aging (54), which can also be considered as the 3rd method of telomere terminal repair. In human cells, telomere HDR activation is usually inhibited by $\mathrm{Ku} 70 / 80$, but in the absence of some subunits of shelterin, such as POT1, very low levels of telomere sister chromatid exchange can be detected even in the presence of Ku70/80 (55). The key to HDR activation is the activation of PARP1, and a variety of mechanisms that inhibit PARP1 activity can prevent HDR. Rai et al (56) found that the shelterin substructure, RAP1, and the basic domain of TRF2 can act together to inhibit the localization of PARP1 to telomeres, thereby inhibiting the telomere recruitment of the HJ dissociation enzyme, SLX4, and ultimately inhibit HDR. In the absence of the basic domain of TRF2 and the RAP1 protein, PARP1, SLX4, and other proteins 

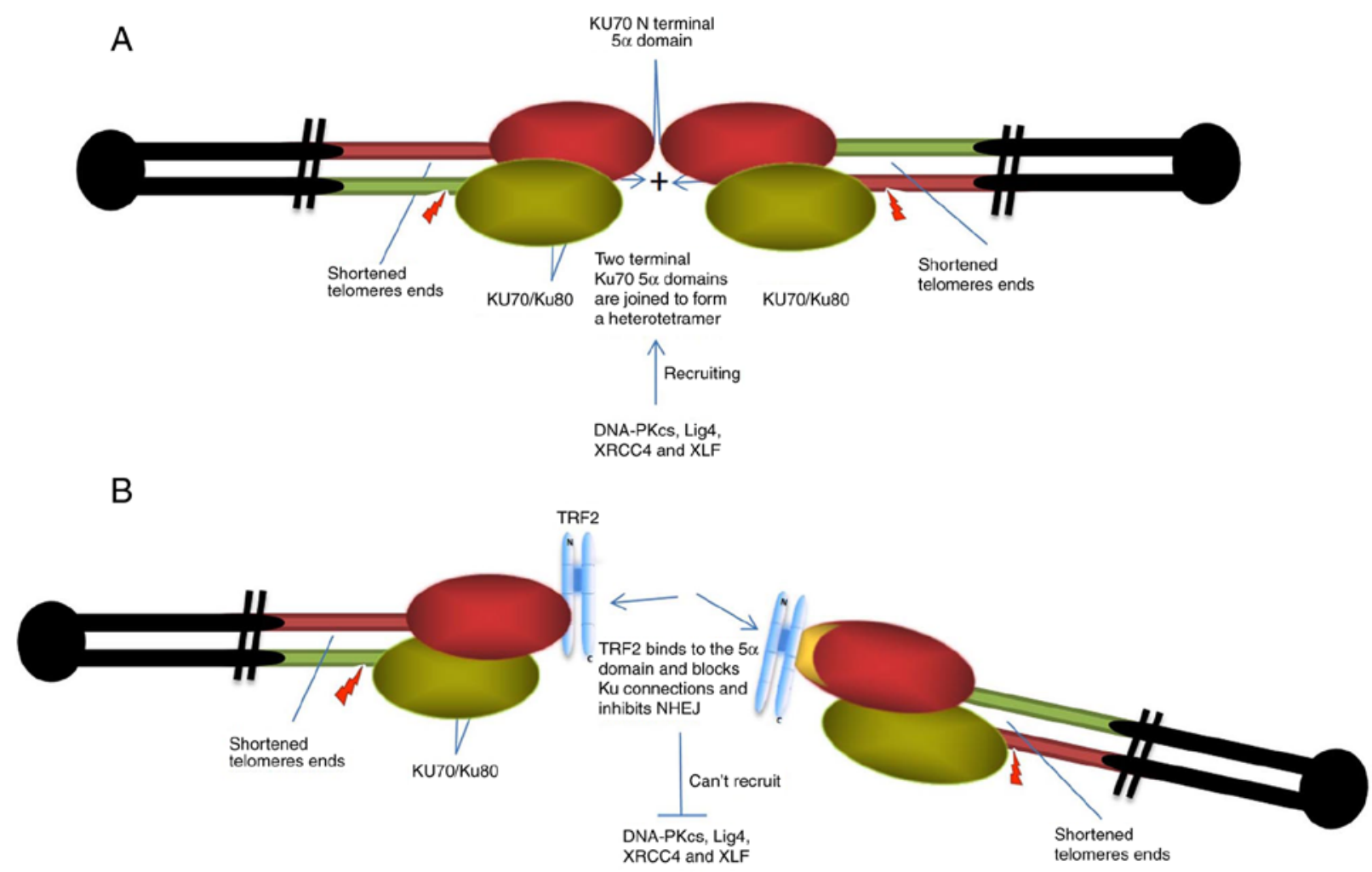

Figure 3. Inhibitory effect of TRF2 on damaged telomere C-NHEJ.(A) The damaged shortened telomere ends bind to the Ku70/80 protein, and via mutual affinity of the Ku70 $5 \alpha$ domains, a Ku70/80 heterotetramer is formed, leading to chromosome end-to-end fusion. (B) TRF2 directly binds to the $5 \alpha$ domain of Ku70 to prevent the formation of the Ku70/80 heterotetramers and inhibits the recruitment to the telomere ends of DNA-PKcs, Lig4, XRCC4, XLF, making the ends unable to be effectively connected. TRF2, telomeric repeat-binding factor 2; C-NHEJ, canonical non-homologous end joining; DNA-PKcs, DNA-dependent protein kinase catalytic subunits; Lig4, DNA ligase IV; XLF, XRCC4-like factor.

involved in HDR (for example, Mus81 and Sgs1), promote the rapid resection of T-loop structure telomeres, telomere loss, and the formation of chromosome ends without telomeres, eventually leading to an extensive telomere-free chromosome fusion in virus specific $\mathrm{T}$ cells (56). With respect to the related mechanism, as the local loss of TRF2 activates PARP1, the PARsylation of PARP1 can lead to the recruitment of the SLX4-SLX1-Mus81 HJ dissociation enzymes (57). These HJ dissociation enzymes may cleave the T-loop 3-way connection, but will not cause loss of telomeres or untie the T-loop, which promotes HDR. However, in the absence of the TRF2 basic domain, the 3-way connection can freely branch and migrate, thereby potentially forming a dHJ (31). Treatment of $\mathrm{dHJ}$ by $\mathrm{HJ}$ dissociation enzymes may result in the excision of telomere DNA in the loop. The TRF2 basic domain can bind to the 3- or 4-way connection of DNA. This binding is not related to the DNA sequence and has similar affinity for these 2 structures (dissociation constant, $200 \mathrm{nM}$ ) (31). TRF2 binds to the 3-way connection at the base of the telomere T-loop, which can mask the PARP1 activation site at the $5^{\prime}$ concave end, inhibits the recruitment of SLX4 and other endonucleases (Mus81), and also stabilizes the 3-way connection, inhibits branch migration, avoids the formation of $\mathrm{dHJ}$, and ultimately prevents T-loop cleavage (31). However, investigation of this mechanism did not reveal that RAP1 has a synergistic effect with TRF2 in inhibiting PARP1 or T-loop cleavage (54), which is inconsistent with the aforementioned results, and further research is required (31).
In summary, following telomere damage and shortening, the DDR cascade is activated, and the 3 end-repair methods, C-NHEJ, A-NHEJ and HDR may be triggered, according to the characteristics of the internal environment of the cell nucleus. This abnormal repair leads to telomere dysfunction and CIN. Surviving cells change with the cell cycle, and abnormal replication and mitosis will produce a variety of random DNA recombination mutations.

Regulation of telomere length by TRF2. Telomere length is associated with chromosome stability. Telomeres are severely shortened and lose the protective effect of shelterin substructures, which can cause CIN, and abnormal expression of the telomere protein can also cause changes in telomere length, which also affects chromosome stability (58). TRF2 is a key player in telomere protection and telomere length maintenance. It can prevent loss of T-loops and is also a negative regulator of telomere length. For example, the overexpression of TRF2 leads to shortening of telomeres in normal primary fibroblasts and telomerase-positive lung, liver and gastric cancer cells (59-61). Previous studies have found that the mechanism of TRF2 and cell telomere length regulation is associated with the following aspects. i) On the one hand, as aforementioned, the interaction of the $\mathrm{N}$-terminal basic domain of TRF2 with the dissociation enzyme-related protein, SLX4, and different types of endonucleases involved in dissociation activities, such as GEN1 and MUS81, prevent the cutting of telomeres (62). Furthermore, various types of dissociation 
enzyme, such as SLX4 and GEN1 activities are checked via this domain to promote the precise repair of stalled forks, which occur during telomere replication (62). On the other hand, the TRF2 homodimerization domain can recruit SLX4, which is also a structure-specific DNA repair nuclease scaffold, and can recruit the Holliday ligation enzyme, SLX1 and other nucleases (GEN1 and MUS81) to the telomeres to prevent telomere damage, lengthening and fragility, and plays multiple roles in regulating telomere homeostasis (63). ii) TRF2 promotes telomere shortening via the DNA repair endonuclease $\mathrm{XPF}$-excision repair cross complementation group 1 (ERCC1) enzyme complex. XPF-ERCC1 serves as a structure-specific endonuclease, involved in nucleotide excision repair, cross-linking repair and DNA recombination $(61,64,65)$. In the absence of the XPF-ERCC1 nuclease, K5-TRF2 mice, which overexpress TRF2, did not exhibit significant telomere shortening, suggesting that the TRF2-bound XPF enzyme rapidly degrades telomeres in the presence of increased TRF2 expression (61). Therefore, telomere shortening promoted by TRF2 requires the function of XPF-ERCC1. An in-depth study has demonstrated that the nuclease activity of XPF-ERCC1 was essential for nucleotide excision repair, but the XPF-ERCC1 mutant protein, without nuclease activity, could also induce TRF2-mediated telomere shortening, revealing that the role of XPF-ERCC1 was unrelated to its nuclease function, and this phenomenon was conserved between mice and humans; therefore, the specific mechanism of action requires further investigation (64). XPF-ERCC1 can also negatively regulate the binding of TRF 2 and telomere DNA. Introducing wild-type XPF into XPF-deficient cells (human Phoenix andGM08437B cells) was shown to reduce the association between TRF2 and telomere DNA by $>40 \%$. If the function of its nuclease domain is still lost, the aforementioned effect can be eliminated. These findings indicated that XPF-ERCC1 controls TRF2 and telomere length maintenance via 2 unique mechanisms (65). iii) The TRF2-mediated growth factor heregulin (HRG) $\beta 2$ is a negative regulator of telomere length. Co-immunoprecipitation and imaging experiments demonstrated that HRG $\beta 2$ could be partially localized at the end of chromosomes, bind to and interact with RAP1/TRF2 $(66,67)$. Overexpression of HRG $\beta 2$ promoted notable upregulation of TRF2 protein expression, while knockout of the protein markedly reduced the protein expression level of TRF2 $(66,67)$. In non-invasive, HRG-negative MCF-7 breast cancer cells, engineered overexpression of the HRG $\beta 2$ subtype resulted in notable shortening of the telomeres; in highly invasive, HRG-overexpressing MDA-MB-231 and Hs578T cells, antisense-mediated HRG $\beta 2$ inhibition could increase telomere length $(66,67)$. Therefore, the telomere length regulation function of HRG $\beta 2$ may be associated with its regulation of TRF2 $(66,67)$. iv) TRF2 can regulate the expression of human telomerase reverse transcriptase (hTERT), a telomerase rate-limiting catalytic protein component. Telomerase is an important factor in the regulation of telomere length, but it is mostly in a state of expression inhibition in somatic cells (68-70). A previous study found that subtelomere genes were regulated by the telomere length-dependent loop (telomere position effect over long distances; TPE-OLD), which silences subtelomere genes by affecting telomere position (68). The TERT gene is a megabase in length, from the end of the human $5 \mathrm{p}$ chromosome.
Cells with long telomeres at the end of the $5 \mathrm{p}$ chromosome form a telomere chromatin loop in the hTERT site domain, which inhibits hTERT expression (68). It was found that TRF2 knockdown notably reduced the interaction between telomere and the hTERT locus, suggesting that TRF2 may be involved in the T-loop interaction on the hTERT locus (68). With respect to the mechanism, with cell aging or telomere shortening and decreased TRF2 level, the chromatin ring and hTERT locus could become separated, and notable epigenetic changes, such as DNA methylation and histone modification, may occur in the hTERT promoter region, which may activate $\mathrm{h} T E R T$ transcription and enhance telomerase activity (68). A previous study further demonstrated that there were frequent interstitial telomeric DNA sequences (ITS) downstream of the TERT site in higher primates (69). Through the interaction with interstitial TTAGGG repeats, TRF2 may be responsible for the interaction between telomere and hTERT ITS in cells with long telomeres, and act on the hTERT promoter to inhibit its expression. When TRF2 protein expression level decreases, the interaction between T-loop and ITS is weakened, which may relieve the inhibition of hTERT, induce the expression of $\mathrm{h} T E R T$ and affect the telomerase activity assembly (69).

TRF2 extratelomeric epigenetic regulation function. TRF2 can bind to a specific sequence of dsDNA via its C-terminal Myb domain. In addition, there is another broader non-ds binding method. Studies have found that, in the human genome, TRF2 has thousands of binding sites outside the telomeres and is associated with the whole genome $(70,71)$. This association enables TRF2 to participate in extratelomeric DNA repair and gene transcription regulation (71-73). The repetitive guanine-rich sequence can form a 4-stranded DNA tetramer structure in solution (74-77) and TRF2 is one of the few proteins with specific high affinity for this structure $(78,79)$. This affinity requires the $\mathrm{N}$-terminal basic domain of TRF2 and the C-terminal DNA-binding domain to collaborate, and its affinity is stronger than the specific sequence of dsDNA (73). Therefore, a large part of non-telomere TRF2-binding sites are composed of non-ds G-quadruplexes (G4s). The G4 motif is a DNA secondary structure. The core structure of the G4 motif comprises stacked planar tetrads of guanine residues stabilized by Hoogsteen base pairing (74). It is considered to be a global gene regulatory motif and this function requires interaction with a transcriptional regulatory protein specifically associated with G4s. G4s are abundant in gene promoters and are evolutionarily conserved in a variety of animals and microorganisms, such as human, chimpanzee, mouse and rat, and several kinds of bacteria (Escherichia coli and Saccharomyces cerevisiae) $(74,75,80)$. There are extensive TRF2-G4 associations in the entire genome and they regulate gene expression in a G4s motif-dependent manner (70). The interaction between non-telomere TRF2 and promoter G4s induces gene regulation via epigenetic modification, leading to the activation or silencing of histone marker genes. It has been demonstrated that, following binding of TRF2, histones are modified, resulting in transcriptional inhibition of 8 out of 9 genes, changing the expression and epigenetic status of the target promoter (70).

p21 (also known as CDKN1A), a CDK inhibitor, is negatively regulated by TRF2 in a G4-dependent manner, i.e., loss of 
TRF2 can enhance the activation of p21 (72). This is achieved by TRF 2 by recruiting the REST-co-REST-LSD1 inhibitory complex. The activation of p21 leads to cell cycle arrest and apoptosis/senescence, which is the key mechanism underlying the action of DNA damage-inducing anticancer drugs. In cancer cells (HT1080 fibrosaroma and MDA-MB-231 breast cancer cell lines) with relatively higher TRF2 protein expression levels, p21 activation was found to be notably reduced following drug treatment, suggesting that it is associated with drug resistance $(72)$.

The G4 structure, -600 bp upstream of the hTERT promoter, determines the occupancy rate of TRF2 in this promoter. Following TRF2 knockdown, the TRF2 occupancy rate of $\mathrm{G} 4 \mathrm{~s}$ in the promoter decreases, which can induce the transcriptional activation of hTERT (81). This is due to the polycomb inhibitor polycomb repressive complex 2 (PRC2) in the hTERT promoter being dependent on TRF2 recruitment. PRC2-induced H3K27 inhibits histone-tagged trimethylation, leading to the inhibition of $\mathrm{hTERT}$. The $\mathrm{G}$ to A mutation in the cancer-specific and highly recurrent hTERT promoter disrupts the TRF2-G4 interaction. This mutation has been associated with several types of cancer, including glioblastoma, melanoma, hepatocellular carcinoma and urothelial carcinoma (81-85). It destroys the G4 structure in the hTERT promoter, inhibits the binding of TRF2 to the promoter and eliminates the inhibitory effect of the PRC2, resulting in the reactivation of $\mathrm{hTERT}$. Therefore, the epigenetic regulation of hTERT, caused by the interaction of TRF2-G4, may be of notable value for the treatment of various types of cancer (81). In addition, there are numerous epigenetic modifications in tumor regulatory genes that cancer cells rely on for survival, all of which are associated with the TRF2 occupancy rate of the G4 structure in their respective promoters, such as $c-M Y C, K R A S$ and VEGF (86-89). This shows that, apart from telomeres, TRF2 is crucial for the expression and epigenetic modification of tumor regulatory genes. A previous study found that the epigenetic status and expression of numerous TRF2 target promoters, located at a great distance from telomeres, are sensitive to telomere length (90). The TRF2 occupancy rate of long telomeres at remote genomic sites is usually low. On the contrary, when the telomeres are relatively short, the non-telomere TRF2 binding increases notably (90). This telomere length-sensitive promoter TRF2 occupancy rate changes, resulting in epigenetic modification of the promoter. A previous study referred to this as a telomere segregation and partition (TSP) model, which can affect telomere-dependent gene expression in the whole genome (91). TSP is different from the TPE-OLD model, as the TPE-OLD model only affects genes $\sim 10 \mathrm{Mb}$ from the telomere (91). With telomere shortening, the distribution of TRF2 inside and outside the telomere changes correspondingly. Under the combined action of related cofactors or gene mutations, senescent cells exhibit dual characteristics of activation or inhibition of transcription epigenetic modification, which eventually leads to the inhibition of tumor suppressor genes or the promotion of oncogene expression.

In summary, in mammalian cells, TRF2 is notably associated with telomere length, involving a variety of regulatory mechanisms and markedly affecting gene expression. Chromosome stability depends on the telomere structure of sufficient length. Within a certain range, the abundance of telomere binding protein is positively correlated with the length of telomere DNA repeats. An increase or decrease of TRF2 expression level can cause changes in telomere length. When the critical length of telomeres is reached, causing CIN, the genome is prone to mutations affected by a variety of environmental factors for example, ionizing radiation and mutagenic compounds. When affected by telomerase or selective telomere lengthening mechanisms, telomeres can maintain their critical length and prevent further shortening. This hypothesis is consistent with the fact that tumor cells have short telomeres. At this time, under the telomere protection or extra-telomeric regulation of TRF2, pathological responses, such as DDR or end-to-end connections, that induce cell proliferation arrest or apoptosis, cannot be evoked, which maintains the cell cycle, promotes cell proliferation and growth, and generates immortal cells. As these cells grow and proliferate, gene mutations gradually accumulate, which may eventually induce the development of a variety of tumors.

\section{Association of TRF2 dysfunction with CIN and tumor formation}

CIN refers to the increase in the frequency of chromosome gain or loss in the process of cancer cell division compared with that in normal cells, which leads to the decrease in the stability of the genome and induces a variety of mutations, such as polyploid or aneuploid formation. CIN is one of the hallmarks of cancer and is attributed to errors in chromosome separation during mitosis $(92,93)$. CIN plays an important role in cancer by accelerating the accumulation of genetic changes responsible for the transformation of cancer cells and is the main driving factor behind tumor development (92-94). CIN may occur through a variety of mechanisms, including cell cycle regulation, DDR, DNA replication, chromosome segregation and telomere dysfunction.

Telomeres form protective caps at the ends of linear chromosomes to prevent nuclear degradation, end-to-end fusion, irregular recombination and $\mathrm{CIN}$, and protect them from loss of genetic information and inappropriate handling when DNA is damaged. Telomeres are crucial for preserving the integrity and stability of chromosomes $(49,95)$. It is hypothesized that tumor formation is suppressed by 2 replicative senescence and crisis (96). Under normal genetic and epigenetic background conditions, telomeres shorten with each cell division (physiological telomere wear), and finally stop cell proliferation by activating DDR, which regulates the life span of somatic cells and limits their renewal ability (96). If cells lose the checkpoint function, the ability to protect the ends of linear chromosomes from end-to-end fusion is eventually lost. A previous study revealed that the state of the telomere complex and the length of the telomere sequence was associated with chromosome stability (97). Specifically, telomere complex protein damage or abrasion telomere shortening activated THE ATM and ATR kinases via unprotected chromosomal ends, induced the DDR cascade, and caused cell cycle arrest. During this period, cells try to repair the damage. If the DNA damage cannot be repaired, the senescence response is triggered, which exerts an antitumor effect $(98,99)$; on the other 
hand, the loss of telomere protection and cycle checkpoint blockade may lead to a telomere crisis, which is characterized by further shortening of dysfunctional telomeres and extensive chromosomal fusion. Cells in this critical state will produce extensive apoptosis (100). End-to-end fusion of chromosomes during the telomere crisis can cause spontaneous mitotic arrest. During the period of spontaneous mitotic arrest during the telomere crisis, telomere deprotection is a potential molecular signal leading to cell death. The destruction of TRF2 leads to rapid mitotic cycle stagnation or cycle extension, which is an important signal leading to cell death (101). Since most cell deaths before the crisis are associated with mitosis arrest, it is hypothesized that prolonging mitosis is the main mechanism that restricts senescence and prolongs cell lifespan (101). Telomere crisis represents a highly unstable state of the genome and entering the break-fusion-bridge (BFB) cycle via end-to-end chromosome fusion is a classic mechanism underlying telomere-driven genome instability. The dysfunctional telomeres fuse with the ends of other chromosomes to produce dicentric chromosomes to initiate the anaphase bridge-dependent cycle $(6,102,103)$. Anaphase chromatin bridges may or may not be broken, leading to numerous structural rearrangements, segment duplication or abnormal separation of polyploid chromosomes (103). Chromosomal rearrangements commonly associated with telomere dysfunction include irreversible translocation, region amplification and segment deletion, and non-segregating events that lead to aneuploidy. These dicentric chromatids formed by the replication and fusion of sister chromatids will participate in the fusion bridge breaking cycle until new telomeres are added to the free ends, leaving multiple segments of DNA amplification and deletion accumulation (103). Segment duplication may lead to increased expression of genes located in the amplified region, which is one of the mechanisms underlying oncogene activation. This can also confer resistance to chemotherapeutic drugs by increasing the number of copies of genes encoding drug targets (103). In brief, these rearrangements can produce chimeric genes or oncogene disorders, as well as changes in gene dosage required to induce tumorigenesis. In the absence of functional tumor suppressor genes, they can promote cancer occurrence (104-106). Therefore, CIN promotes the malignant transformation of precancerous cells at the genetic level. With the delayed activation of telomerase or alternative elongation mechanisms, precancerous cells can achieve unlimited replication capacity and immortality and, ultimately, complete cancerous transformation (Fig. 4).

TRF2 plays a crucial role in regulating molecular events, which maintain telomere integrity (107). The abnormally high or low expression level of TRF2 may lead to CIN and induce fatal tumor changes. In some types of cancer (such as breast cancer, stomach cancer and hematological malignancies), TRF2 expression is reduced (108-110). With respect to the underlying mechanism, TRF2 knockdown could destroy the T-loop structure and deprive telomere ends of protection. SLX4, GEN1 and MUS81 lack TRF2 regulation, which can cause telomere shortening (62); in addition, it has been demonstrated that the amino-terminal basic domain of TRF2 binds to the histone $\mathrm{H} 2 \mathrm{~A}$ isotype protein, $\mathrm{H} 2 \mathrm{ac}$, and recruits $\mathrm{H} 2 \mathrm{ac}$ to the telomeres to participate in the regulation of telomere structure and/or function (111). The loss of H2ac may lead to the accumulation of telomere-related ATM-dependent DNA damage factors in H2ac-deficient cells, DDR, rapid loss of telomere repeats and G-rich strand loss (111). Telomere loss or damage can induce dysfunction, trigger DNA damage signal transduction, block cell cycle progression and induce cell aging and apoptosis. Some mutant cells can bypass cycle arrest, enter telomere crisis, accelerate improper repair, produce chromosome end-to-end fusion, initiate the BFB cycle, cause genomic instability and promote tumorigenesis (101). It was found that TRF2 knockdown could induce the expansion and metastasis of cancer stem cells (CSCs), while reducing the number of CD34+ stem cells $(112,113)$. This reveals that the change in telomere length regulation mediated by TRF2 deficiency has a profound impact on stem cells $(40,114)$. This effect involves epithelial-to-mesenchymal transition (EMT) caused by the expansion of CSCs (115), as well as the overexpression of telomerase and the ALT mechanism, which promotes the formation of metastatic tumors $(116,117)$. The genetic and biological characteristics of these TRF2 deletion-mediated metastatic CSCs require further research for characterization.

The overexpression of TRF2 may also play an important role in the fate of cancer cells. Notable increases in TRF2 protein expression levels have been reported in a group of human cancers (such as epithelial carcinogenesis, gastric cancer and liver cancer) (118-120). The overexpression of TRF2 could accelerate the telomere erosion rate of human primary cells (UMUC3 bladder cancer cells) in the absence of telomerase, and even trigger DDR $(121,122)$. A previous study (123) found that most chromosomal fusions induced by TRF2 overexpression were accompanied by extensive deletions involving subtelomere regions of chromosomes, causing sustained DNA replication stagnation, and the chromosomal ends were severely shortened randomly, whereas the fusion of these chromosomes usually contained microhomologous regions of 1 to 6 nucleotides. The mechanism may be as follows: TRF2 overexpression leads to the formation of excessive compact DNA-protein complexes and the binding of the TRF1 protein, which promotes telomere replication, to telomeres decreases, thereby hindering the development of telomere replication forks, leading to telomere DNA replication stagnation. The resulting decomposition of telomeric ultrafine anaphase bridges results in the random loss of large fragments of telomere sequences and subtelomere regions. Then, via the selective A-NHEJ repair process, the broken chromosomes are fused, which eventually leads to CIN $(123,124)$. In addition, as aforementioned, the telomere shortening promoted by TRF2 also requires XPF-ERCC1 cooperation, which is unrelated to its endonuclease function, and the mechanism underlying its association with TRF2 overexpression leading to replication fork arrest requires further in-depth investigation. Another study demonstrated that TRF2 was overexpressed in colorectal cancer tissues and in the SW480 cell line, and the mechanism was associated with the transcription factor, Sp1, which is involved in the upregulation of TRF2 expression (125). It has also been demonstrated that the promoter of TRF2 is rich in GC sequences (70-75\%), and there was no notable TATA box. $\mathrm{Sp} 1$ is a multi-gene family member with sequence-specific DNA binding to the $\mathrm{C}$-terminal zinc finger motif (126-128). It activates transcription by binding to the GC/GT box and plays a key role in the regulation of gene expression in mammals lacking the TATA box $(126,127)$. Sp1 regulates cancer-related targets, including 


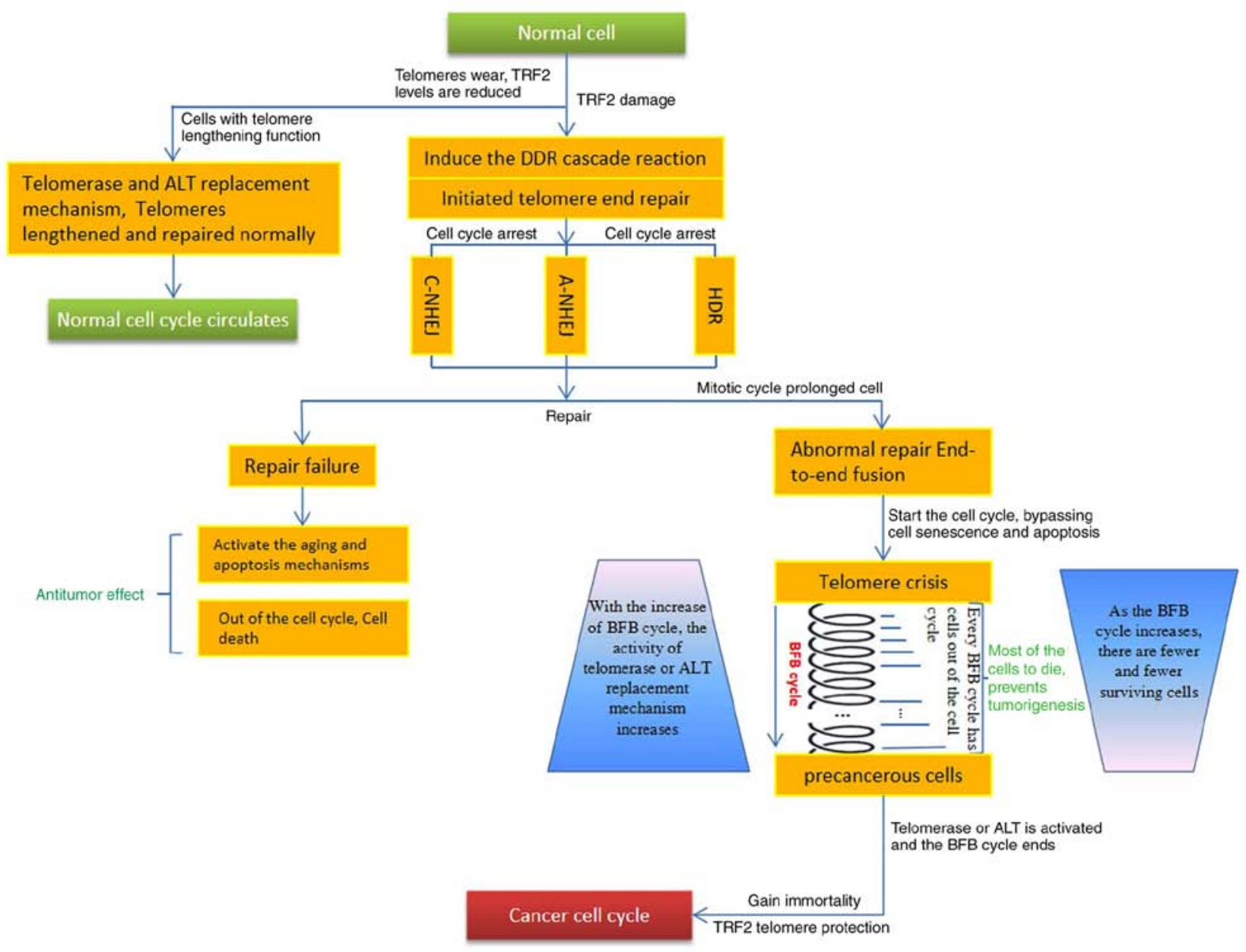

Figure 4. Abnormal function of telomere TRF2 leads to the transformation of normal cells into tumor cells. The chromosomal telomeres of normal cells display shortening, TRF2 localization and functional damage due to replicative senescence and other causes such as Drugs, radiation damage, and induce DDR and abnormal telomere end repair. A proportion of the cells that fail to repair are eliminated due to the initiation of the senescence and apoptosis mechanisms. Another proportion of the cells, due to the prolonged mitotic cycle, bypass senescence and apoptosis, and are abnormally repaired, exhibiting telomere end fusion and entering a telomere crisis period. During this crisis period, the chromosomes are extremely unstable and are reorganized on a large scale, which manifests as the BFB cycle. During each $\mathrm{BFB}$ cycle, most of the cells die, which can reduce the number of precancerous cells. A small number of surviving cells exhibit gradually activated telomerase and ALT telomere substitution activity due to a variety of factors (such as genetic mutations), resulting in telomere extension and ending of the BFB cycle. TRF2 binds the repeat sequence on the lengthened telomere, protects the newly formed telomere and reduces chromosomal instability. At this time, the recombinant cells (precancerous cells) become immortal and evolve into cancer cells. TRF2, telomeric repeat-binding factor 2; DDR, DNA damage response; BFB, break-fusion-bridge; ALT, alternative lengthening of telomere; C, canonical; NHEJ, non-homologous end joining, A, alternative; HDR, homologous recombination repair.

PDEGF, p21, VEGF, TGF $\beta$, cyclin D1, E2F1, c-Fos, TGF- $\alpha$ and osteopontin, which are key transcription factors caused by cancer (128-130). Therefore, it was hypothesized that, in certain types of tumor cells (such as human colon adenocarcinoma WiDr and Caco-2 cell lines), Sp1 may also upregulate the expression of TRF2 and induce tumor development $(129,130)$. In addition to Sp1, $\beta$-catenin has also been shown to activate TRF2 transcription. The overexpression of the transcription factor complex $\beta$-catenin/T-cell factor (TCF)1E leads to an increase in TRF2 protein expression level and its binding to telomeres to confer telomere protection (131). By evaluating the number of TIF, i.e., the number of telomere foci co-localized with 53BP1 immune signal, it was confirmed that changes in $\beta$-catenin expression affected telomere protection (131). In addition, it was recently demonstrated that the expression level of TRF2 and TRF1 could also be regulated by the chromatin remodeling complex, BRM-SWItch/sucrose non-fermentable (SWI/SNF) (132). BRM could be recruited to the promoters of TRF2 and TRF1, which provides a basis for effective transcription, and also raises the possibility that several other identified or unknown factors may collaborate with BRM-SWI/SNF to regulate the transcription of TRF2 and TRF1, whereas its deletion reduces the mRNA and protein expression levels of TRF2 and TRF1 (132). In addition, the TERF2 gene has a typical $\mathrm{CpG}$ island around its transcription start site. The hypomethylation of the TRF2 gene promoter and the $\mathrm{CpG}$ island of exon 1 is one of the important mechanisms underlying TRF2 gene upregulation, and hypomethylation may be involved in the upregulation of TRF2 in gastric cancer (133). The microRNAs (miR) miR-23a and miR-155 inhibited the translation of TRF2 and TRF1 by targeting the 3 untranslated regions of their transcripts $(134,135)$.

A schematic diagram of the factors involved in the TRF2 tumor formation-promoting effect is shown in Fig. 5.

\section{TRF2 and tumor angiogenesis}

The role of TRF2 in cancer depends not only on its protective effect on telomeres, but also on its ability to regulate gene 


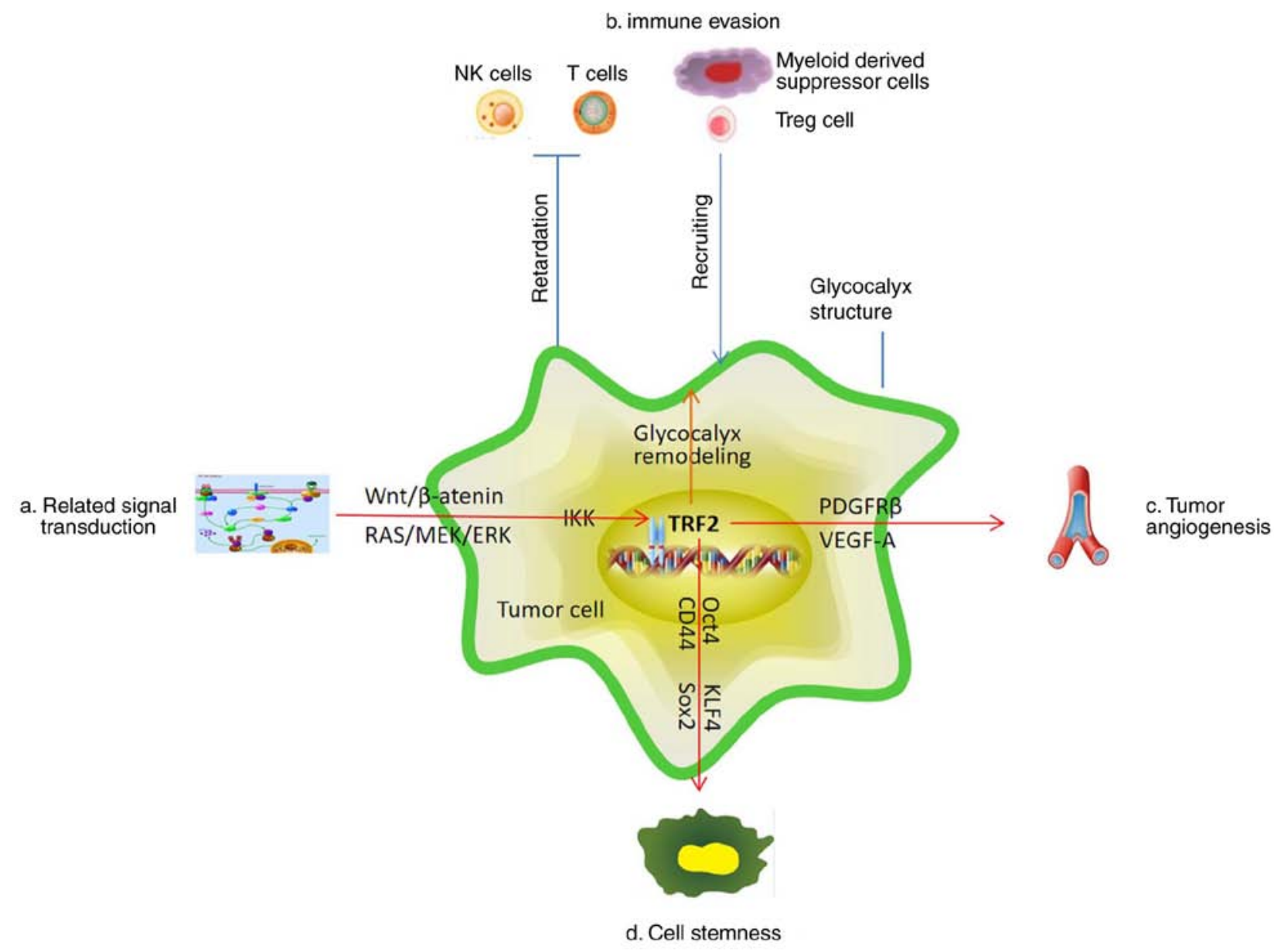

Figure 5. Schematic diagram of the TRF2-tumor promoting effect. (a) Transduction via signaling pathways, such as Wnt, RAS and IKK, upregulates, activates and stabilizes TRF2 molecules in tumor cells, and stimulates internal and external regulatory mechanisms that are conducive to tumor development via regulation of epigenetic changes or gene expression. (b) TRF2 reconstitutes the glycocalyx via gene regulation of glycocalyx components outside the cell membrane, thereby recruiting myeloid-derived suppressor cells, suppressing immune effector cells, and producing immune escape. (c) TRF2 promotes the formation of vascular endothelial cells in the tumor cell microenvironment and promotes tumor angiogenesis via the regulation of tumor angiogenesis factor expression. (d) TRF2 maintains the characteristics of tumor stem cells by regulating the gene expression and stability of tumor cell stemness-related transcription factors and related proteins, thereby promoting tumor cell proliferation and cancer metastasis. TRF2, telomeric repeat-binding factor 2; IKK, IKB kinase; NK, natural killer; Treg, regulatory T cells.

expression. Angiogenesis is important for the progression of malignant tumors. A previous study found that TRF2 and Wilms' tumor suppressor 1 (WT1) were highly expressed in the blood vessels of tumors in patients with prostate, pancreas, breast, lung and kidney cancer, and TRF2 co-localized with WT1 in vascular endothelial cells (7); however, it was not expressed in the blood vessels of healthy adjacent tissues, further proving that TRF2 was the transcription target of WT1. WT1 binds to and activates the TRF2 promoter in human endothelial cells to promote TRF2 expression. TRF2 can stimulate the migration, proliferation and formation of tube-like structures by endothelial cells, thereby increasing tumor angiogenesis (7). Knockdown of TRF2 could suppress the angiogenic properties of endothelial cells. The specific mechanism could be that TRF2 binds to and transactivates the gene promoter of platelet-derived growth factor receptor $\beta$ (PDGFR $\beta$ ) in tumor endothelial cells, which promotes PDGFR $\beta$ expression on the tumor endothelial cell membrane, thereby enhancing the formation of the tumor vascular network and promoting tumor growth (7). This effect was independent of the telomere-protective effect of TRF2 (7). Another study found that TRF2 could notably affect the expression level of VEGF-A in the 'secretory body' of cancer cells (136). There was a positive correlation between high levels of TRF2 and VEGF-A, which promoted endothelial cell differentiation and angiogenesis, and it may be used as a new type of tumor prognostic marker to identify high-risk colorectal cancer subgroups (136). The underlying mechanism could be due to the combination of TRF2 and distal regulatory elements, which can promote the expression level of sulfatase 2 (SULF2), an endoglucosamine-6-sulfatase, and is a heparan sulfate proteoglycan (HSPG) catabolic enzyme. By inducing the post-synthesis modification of HSPGs, TRF2 weakens HSPGs ability to bind and isolate signaling molecules containing heparin-binding domains, including VEGF-A, thereby inhibiting the binding of VEGF-A to the plasma membrane, which can affect tumor vascularization and, consequently, tumor growth and metastasis (137). Clinically, TRF2/SULF2 expression level may be a biomarker of poor prognosis for patients with colorectal cancer (CRC) (137). Therefore, compared with the classic antitumor neovascularization therapy, using TRF2 as a therapeutic target may represent a major development in CRC therapy. 


\section{TRF2 and tumor signal transduction pathways}

TRF 2 expression is regulated by the Wnt/ $\beta$-catenin signaling pathway. As aforementioned, the $\mathrm{Wnt} / \beta$-catenin signaling pathway activates the expression of TRF2 and maintains the level of TRF2 that is essential for telomere protection in human cancer cells, normal cells and mouse intestinal tissues (131). The canonical Wnt signaling pathway activates and stabilizes $\beta$-catenin, translocates to the nucleus, then combines with members of the TCF-lymphoid enhancer factor (LEF) transcription factor family to activate gene transcription (131). Analysis of the human TERF 2 gene using the Ensembl genome database (http://grch37.ensembl.org/index.html) revealed a potential regulatory region (termed Reg) downstream of the transcription start site (131). The TERF2-Reg sequence contains 6 putative TCF-LEF transcription factor-binding sites. The overexpression of $\beta$-catenin alone, or the co-overexpression of $\beta$-catenin and TCF-LEF induced specific activation of the natural Reg region $(131,138)$. The expression level of $\beta$-catenin also determines the expression level of the RAP1 gene encoding the TRF2-interacting protein. These results indicated that $\beta$-catenin regulated telomere protection by regulating the level of TRF2. Using gene knockout mice, reducing the expression of the $\beta$-catenin gene, Ctnnbl, could trigger an increase in telomere TIF, which was accompanied by a decrease in cell viability and an increase in the percentage of cells expressing $\beta$-galactosidase (a marker of cellular senescence) (131). Typically, in normal and cancer cells, either in mice or humans, the activation of Wnt/ $\beta$-catenin signaling leads to an increase in TRF2 expression levels and enhanced telomere protection $(131,138)$, which is also one of the important mechanisms of abnormal proliferation of tumor cells.

TRF2 stability in cells is regulated by the RAS/RAF/MEK/ERK signaling pathway. In addition to playing a key role in cancer cells, the RAS/RAF/MEK/ERK signaling pathway also represents one of the most important pathways required for growth control, normal development, differentiation and environmental response in the majority of tissues. Throughout the cell cycle, subtle regulation of ERK1/2 activity is important for $\mathrm{G}_{1} / \mathrm{S}$ and $\mathrm{G}_{2} / \mathrm{M}$ transition $(139,140)$. ERK $1 / 2$ activity decreases in the $S$ phase compared with that in the $\mathrm{G}_{1}$ and $\mathrm{M}$ phases; however, a basic ERK1/2 activity continues throughout the cell cycle (141). TRF2 expression levels and telomere protection are regulated by MAP kinase signaling. Compared with that in the precursor cell line, the expression level of the TRF2 protein is increased in immortalized cells (142). In a variety of human cancers (such as epithelial carcinogenesis, gastric cancer and liver cancer), the expression of TRF2 at the RNA and protein level increases $(8,121)$, and its internal mechanism may be associated with the regulation of TRF2 amino acid residue phosphorylation. As the serine 323 (Ser323) residue of TRF2 is embedded in the MAPK consensus PXSP phosphorylation motif, ERK1/2 and TRF2 interact in different types of cells (including normal as well as cancer cells) $(143,144)$. TRF2 Ser323 can be phosphorylated by ERK1/2, which increases the half-life and stability of TRF2, participates in telomere protection, and promotes tumor growth by maintaining TRF2 levels $(143,144)$. The mutant non-phosphorylated form of TRF2 is unstable and alters telomere termination in a dominant negative manner, triggering telomere uncovering, growth arrest and tumor reversion. Therefore, the constitutive activation of MAPK signal transduction in cancer leads to an increase in TRF2 levels and telomere protection $(143,144)$. These results suggested that telomere stability is dependent on TRF2 phosphorylation, which is regulated by the Ras/Raf/MEK/ERK axis (144).

TRF2 is affected by IKB kinase (IKK) regulation in the signaling pathway. IKK $\alpha$ is known to be a key regulator of tumorigenesis by affecting the NF- $\mathrm{KB}$ signaling pathway (145). The activation of IKK- $\beta$ has been associated with cancer pathogenesis and inflammatory diseases (146). Research on liver CSC revealed that, when the inflammation-related genes, IKK $\alpha$ and IKK $\beta$, were both overexpressed, the interaction between the telomere DNA probe and TRF2 notably increased $(146,147)$. In addition, the loading of POT1, Exo1 and SNM1b on the telomere DNA also increased, and the telomere length notably increased. On the contrary, when a single IKK $\gamma$ was overexpressed, the interaction between the telomere DNA probe and TRF2 was markedly reduced, the loading of POT1, Exo1 and SNM1b on the telomere DNA was also reduced, and the telomere length was notably reduced $(146,147)$. Mechanistically, IKK $\alpha$, IKK $\beta$ and IKK $\gamma$ depended on HP1 to change the methylation of histone $\mathrm{H} 3$ on lysine 27 (H3K27me3). IKK $\alpha$ and IKK $\beta$ enhanced, whereas IKK $\gamma$ inhibited, the competition among HP1 $\alpha, \mathrm{HP} 1 \beta$ and HP1 $\gamma$. Therefore, IKK $\alpha$ and IKK $\beta$ inhibit, whereas IKK $\gamma$ enhances, the activities of H3K27 methyltransferases, SUZ12 and EZH2, regulating the methylation of $\mathrm{H} 3 \mathrm{~K} 27$ in the promoter region of HOTAIR. H3K27me3 negatively regulated the expression level of HOTAIR. HOTAIR exerted carcinogenic effects of IKK $\alpha$, IKK $\beta$ and IKK $\gamma$ in liver CSCs, and promoted the increase in TRF2 and the accumulation of telomere length $(146,147)$. Collectively, these findings indicated that IKK $\alpha$ and IKK $\beta$ increased, whereas IKK $\gamma$ decreased, telomere length and the expression levels of TRF2 and other related protective proteins [POT1, phosphorylated (p)POT1, Exo1, pExo1, SNM1B, pSNM1B/CST-AAF]in liver CSCs, which jointly regulated the proliferation ability of CSCs (147).

In summary, TRF2 exhibits a variety of network connections with tumor regulatory signaling pathways, allowing tumor cells to achieve the networked regulation of multiple signaling pathways of TRF2 protein. Telomere function status, gene expression and functional proteins in the cytoplasm coordinate to promote rapid tumor cell proliferation, invasion and migration, immune evasion and drug resistance.

\section{TRF2 and CSCs}

CSCs are important for the continuous growth, recurrence and metastasis of malignant tumors. Telomere protection protein is an important maintenance component of the biological characteristics of CSCs and the role of TRF2 is particularly important. Short telomeres lacking TRF2 protection can hinder the proliferation of stem cells, affect their tissue regeneration potential and trigger the development of age-related diseases (105). The existence of CSCs mediated by TRF2 has been associated with the drug resistance, invasion and metastasis of cancer syndrome treatment (105). 
Tumor radiotherapy can cause the formation of DSB in irradiated cells and trigger DDR. When DSB cannot be repaired effectively, the cells clear themselves through programmed apoptosis (148). CSCs usually exhibit high TRF2 expression level, which maintains the globular phenotype of tumor stem cells cloned in vitro $(149,150)$. It was previously demonstrated that, after radiation treatment, the expression level of TRF2 and RAP1 in the stem cell cloning sphere increased, and the interaction between the 2 could also regulate the activity of hTERT, which was essential for the maintenance of telomeres (151). Enhanced expression of TRF2, RAP1 and hTERT in stem cell clone spheres could improve telomere DNA repair and protection, and counteract genomic instability caused by telomere shortening or DSB, thereby effectively resisting cell death induced by DNA damage caused by radiotherapy, chemotherapy and other factors (such as aging), maintain the survival of tumor cells, and produce tolerance to treatment (152).

A feature of the ALT mechanism in tumor cells is the assembly of ALT-associated promyelocytic leukemia-nuclear bodies (APBs) on the telomeres. The formation of APBs can induce telomere aggregation, telomere compaction and the concomitant depletion of the shelterin protein TRF2, strongly enrich the phosphorylation of ATM kinase and induce DDR $(152,153)$. Therefore, APBs induce ATM phosphorylation by changing the state of telomere chromatin; thus, inducing DDR and recombinant repair of ALT-positive tumor cells and promoting telomere maintenance (153). TRF2 can regulate cell proliferation and differentiation in APBs by interacting with repressor element 1-silencing transcription factor (REST) via a non-telomere effect. The TRF2-REST complex may play a role in protecting REST from ubiquitin proteasome degradation, thereby maintaining CSCs in an undifferentiated stage (154). Glioblastoma contains self-renewing glioblastoma stem cells (GSCs), which are usually resistant to chemotherapy and radiotherapy. GSCs highly express REST, which may promote their resistance to standard cancer treatments $(155,156)$. TRF2 stabilizes telomeres and REST, and maintains the self-renewal of neural stem cells and GSC (157). Viral vector-mediated infection using short hairpin (sh)RNAs targeting TRF2 mRNA could reduce TRF2 and REST expression levels in the GSCs of patients with glioblastoma, resulting in a decrease in GSC proliferation, while the protein expression levels of L1CAM and $\mathrm{t} 3$-tubulin, which are normally expressed by neurons after mitosis, increases, suggesting that the loss of TRF2 leads to the differentiation of GSCs (157). The loss of TRF2 also renders GSCs sensitive to temozolomide, a DNA alkylating agent used in the treatment of glioblastoma (157). Using TRF2 as a target was shown to notably improve the survival rate of GSCs in a xenograft mouse model (157). These findings indicate a role of TRF2 in GSCs, which includes maintaining stability, ensuring proliferation and chemotherapy resistance, suggesting that TRF2 could be a potential therapeutic target for glioblastoma (157).

Knocking down the expression level of TRF2 could also inhibit the migration potential of oral cancer cell lines, and at the same time reduce the expression of key factors that maintain CSCs in the Cal27 cell line and the generated oral squamous cell carcinoma cells, including CD44, Oct4, Sox2, KLF4, c-Myc, $\beta$-catenin and hTERT molecules (150). Further research found that TRF2 has a strong affinity and interaction with the CSC marker, KLF4, which may be an important mechanism for the maintenance of CSCs, indicating that TRF2 was associated with the transmission of CSC-like phenotypes in oral cancer cells (150).

From the aforementioned results, it may be inferred that TRF2 plays a key role in maintaining the function of CSCs. TRF2 elimination in CSCs could further promote differentiation, loss of the biological characteristics of stemness, increased sensitivity to drugs or radiotherapy, inhibition of EMT, invasion and metastasis of tumor cells, which may improve the efficacy of clinical tumor treatment and long-term prognosis.

\section{TRF2 and tumor immunity}

In human malignant lesions, the increase of TRF2 expression level in some tumor cells (such as epithelial carcinogenesis, gastric cancer and liver cancer) could reduce the recruitment and activation of natural killer (NK) cells, and assist the tumor cells to bypass innate immune surveillance. This is a key step in human tumorigenesis, and it shows that TRF2 controls the biological functions of NK cells and affects tumorigenesis in a DDR-independent manner $(8,158)$. Mechanistically, high TRF2 expression level was found to be associated with the expression level of 3 genes (HS3ST4, GPC6 and VCAN) involved in the biosynthesis of HSPG. These genes all contain an ITS as a binding site for TRF2 $(158,159)$. After binding, TRF2 induces changes in the chromatin structure at the ITS, becomes a TRF2-dependent enhancer element, and activates the expression of neighboring genes (159). The promoting effect of TRF2 on the expression level of the HSPG gene was crucial to the formation of the polysaccharide calyx outside the cytoplasmic membrane, acting as a general remodeling agent of the glycocalyx, as the overexpression of TRF2 changed its overall structure, increased its stiffness and shortened its length (159). Changes in glycocalyx structure change the micro-gradient of cytokines, chemokines and growth factors involved in the recruitment and function of immune cells, which is required for myeloid-derived suppressor cell (MDSC) tumor recruitment. The proteoglycan version encoded by VCAN acts as a toll-like receptor (TLR)2 ligand, and the TLR2 signal activates the immunosuppressive function of MDSCs via the IL-6 autocrine pathway, i.e., IL-6/JAK1/2/STAT3 signaling induces the immunosuppressive autocrine circuit (159). MDSCs are immature myeloid cells with strong immunosuppressive activity, which can trigger the immunosuppressive tumor microenvironment and promote tumor growth (160). In addition, TLR2 signaling also enhanced the immunosuppressive ability of MDSCs on NK cells via a paracrine IL-6/JAK1/2-dependent mechanism. Therefore, this TRF2-dependent HSPG biosynthesis gene regulatory network promoted the recruitment and function of MDSCs, inhibited the recruitment and cytotoxicity of NK cells and immune lymphocytes, and was negatively associated with the overall survival (OS) time in patients with gastric cancer, as it ultimately leads to tumor progression and metastasis (159).

\section{Targeting TRF2 and tumor therapy}

TRF2 is considered as a potential new target for cancer treatment. Inhibition of TRF2 could activate ATM-dependent DDR 
pathways and induce cell apoptosis or senescence (161). When short interfering RNA was used to knockdown the expression level of TRF2 in colorectal cancer and renal epithelial renal cell carcinoma cell lines, tumor cell proliferation and clonal formation were notably inhibited, and cell cycle arrest and apoptosis were markedly induced $(125,162)$. In the xenotransplantation experiment of intracranial tumors, GSCs infected by lentivirus shTRF2 and empty vector were stereotaxically injected into the cerebral cortex of BALB/c nude mice, which lack a thymus. The results demonstrated that the life span of mice in the experimental group was significantly prolonged compared with that in the control group (157). This finding revealed that reducing the expression level of TRF2 may notably improve the survival rate of nude mice in a glioblastoma model. The aforementioned results all indicate that TRF2 may be a new antitumor treatment target. Furthermore, previous studies $(163,164)$ suggest that, compared with that in the previous strategy of inhibiting telomerase to treat tumors, tumor therapy targeting TRF2 may be more effective. The main reasons are as follows: First, telomerase inhibitors were not effective on tumor cells that rely on the ALT mechanism; second, in tumors exhibiting increased TRF2 expression, the therapeutic effect of telomerase inhibitors was not notable (163); reducing the expression level of TRF2 shortened the 3 ' overhangs of telomeres, leading to chromosomal fusion of tumor cells and premature senescence or death of tumor cells. Decreasing the expression level of TRF2 could activate phosphorylated ATM, activating the tumor suppressor gene p53, which is not only an effector molecule downstream of the telomere damage signal, but also one of the main senescence promoters. P53 expresses the E3 ubiquitin ligase, Siah1, and targets TRF2 for ubiquitination and proteasomal degradation (164). TRF2 knockdown further promoted ATM activation; therefore, TRF2/ATM/p53/Siah1 formed a positive feedback loop, which could simultaneously promote telomere decapsulation, induce the p53-mediated cellular senescence signal transduction pathway, and enhance tumor cell suppression (164). Therefore, tumor therapy targeting TRF2 has broad application prospects.

Radio- and chemotherapy play an important role in the treatment of malignant tumors; however, tumor drug resistance remains one of the main obstacles in clinical treatment. An increasing number of studies have found that TRF2 was associated with tumor drug resistance. In radioresistant A549R (telomerase-positive) and U2OSR (ALT mechanism) cells, TRF2 expression was found to be notably increased, while decreasing the expression level of TRF2 notably improved the radiosensitivity of tumor cells (165-167). It has been confirmed that there was a notable negative correlation between telomere length and radiosensitivity $(166,167)$. Knockout of TRF2 may lead to telomere shortening and inhibition of telomerase activity, leading to radiosensitization and shortening of telomeres in A549 and U2OS cells, suggesting that TRF2 may regulate radiosensitization via telomere length and DDR. Orun et al (168) also found the same results while investigating immortalized mesenchymal stem cells, suggesting that TRF2 may be a potential target of radiotherapy for tumors. Ning et al $(169,170)$ found that the expression level of TRF2 in the vincristine-resistant gastric cancer cell line, SGC7901/VCR, and the adriamycin-resistant gastric cancer cell line, SGC7901/ADR, was notably higher compared with that in parental cells. Inhibition of TRF2 expression could notably enhance the sensitivity of drug-resistant cells to cisplatin, adriamycin and etoposide (170). Furthermore, it was found that the expression of ATM, $\gamma$-H2AX and p53 in drug-resistant cells was notably lower compared with that in SGC7901 and, after using shRNA to inhibit the expression level of TRF2, the expression levels of ATM, $\gamma$-H2AX and p53 were notably upregulated, suggesting that TRF2 may promote tumor drug resistance by inhibiting the expression of ATM and its downstream target molecules $(169,170)$. Benhamou et al (171) also found that inhibiting the expression level of TRF2 could notably enhance the sensitivity of oral squamous cell carcinoma cells to EGFR-targeting chemotherapeutics, such as cetuximab and erlotinib, which may become an important development and progress in cancer treatment. It has also been found that, in addition to TRF2 inhibition activating the ATM-dependent DDR pathways and inducing cell apoptosis or senescence, it can also inhibit p38MAPK phosphorylation, block tumor pathway signal transduction and increase chemotherapeutic drug sensitivity (172).

In mice with tumor overexpressing TRF2, a decrease in tumor volume and an increase in OS time were observed following treatment with fluorouracil (5-FU), indicating that TRF2 overexpression may increase the treatment efficiency of 5-FU (159). This was consistent with the MDSC knockdown results, and the enhanced response to 5-FU may be associated with enhanced elimination of MDSCs, allowing the immune system to become reactivated (159). Therefore, the expression level of TRF2 may be an interesting surrogate indicator of response to chemotherapy (159). The use of 5-FU treatment in gastric cancer, gemcitabine treatment in ovarian cancer, and paclitaxel-based chemotherapy in lung cancer (all 3 drugs target MDSCs) could reduce the negative effect of TRF2 overexpression on OS time (173-175). This indicates that the efficiency of chemotherapy is improved in patients with cancer and TRF 2 overexpression.

A previous study (176) showed that the small molecule, curcusone $\mathrm{C}$ may bind to TRF2 via its DNA-binding site, thereby hindering its interaction with telomere DNA, activating the DDR, inhibiting tumor cell proliferation, causing cell cycle arrest and tumor cell apoptosis. Curcusone $\mathrm{C}$ may become a promising lead compound for the treatment of cancer with elevated TRF2. The anticancer activity of other terpenoids may be attributed to their effect on telomere protective protein. Chromosome analysis revealed that As2O3 downregulated the expression level of TRF2, contributing to end-to-end fusion and apoptosis of leukemia cells. Inhibition of TRF2 rendered leukemia cells more sensitive to As2O3, suggesting that TRF2 may represent a promising target for novel leukemia therapies (176).

In summary, maintaining the function of TRF2 is crucial for the control of pathological tumor cell behaviors, such as proliferation, invasion and migration. Overexpression or knockdown of TRF2 may cause CIN, affecting genome expression and cell survival. Regulating the function of TRF2, using artificial methods, to determine the prognosis of tumors, and its potential value in tumor treatment, require further in-depth investigations. Therefore, the research and development of 
TRF2 functional knockdown or function-regulating drugs has broad prospects, and it will likely become one of the important research directions in tumor diagnosis and treatment in the future.

\section{Conclusion}

Accumulating evidence indicates that the telomere and non-telomere-related functions of the TRF2 protein play a key role in the regulation of cell lifespan, chromosome stability, DNA repair or replication, and the extracellular microenvironment (5-8). TRF2 links multiple functions or signaling pathways, which cells rely on for survival and reproduction, performs systemic regulation, enhances cell environment adaptation and survival ability, assists with the elimination of senescent mutant cells, and maintains the stability of genetic material $(49,95,131,143)$. When replicative aging or other pathological factors (such as ionizing radiation) cause TRF2 dysfunction, cell physiological balance is severely disrupted, telomeres lose protein protection, telomere caps are eliminated, DDR is triggered, cell cycle is arrested, DNA is abnormally repaired, and end-to-end fusions occur. At this time, the chromosome is already unstable and is easily mutated (96-99). Due to cell checkpoint blockade, most cells undergo senescent apoptosis during this period to maintain the genetic stability of the body. However, a small number of cells may induce mutations, such as in p53 protein, which is common in most malignant tumors or abnormal expression of TRF2, disrupting the DDR cascade and, by extending the mitotic arrest cycle, bypassing the DDR-induced apoptosis mechanism and entering the telomere crisis period (100). During the telomere crisis, chromosomes are recombined via the BFB cycle DNA to generate large-scale mutant cells, referred to as precancerous cells. Finally, at the end of this cycle, telomerase expression or the ALT mechanism is activated to extend local telomeres, and gradually stabilize chromosomes under the protection of TRF2, forming immortal cells $(6,101-103)$. This may be the stagewise mechanism underlying the transformation of normal human cells to malignant cells. Due to the uncertainty and randomness of DNA recombination in the BFB cycle, the mutation itself is heterogeneous and can generate the same immortal cells with heterogeneous characteristics, which may be an important origin of tumor heterogeneity (104-106). Subsequently, tumor cells have a telomere lengthening mechanism, due to the abnormal proliferation; however, the telomere remains relatively short, and the chromosome is only in a relatively stable state, which can produce subsequent gene recombinations. This may be the basis of mutations and typing of various subtypes of tumor cells (104-106). After the formation of immortalized tumor cells, the increase in TRF2 expression levels has an effect on the structure of the glycocalyx outside the tumor cell membrane and constitutes a microenvironment conducive to tumor growth. In this microenvironment, chemotactic aggregation of immunosuppressive MDSCs, and paracrine immunosuppressive factors, inhibit the tumor killing activity of NK cells and T lymphocytes (8,157-159). Furthermore, TRF2 acts synergistically with multiple signaling pathways in tumor cell proliferation and migration to maintain its own intracellular levels and promote tumor development $(131,138,141,142,144,146,147)$. The function of TRF2 is also indispensable for maintaining the stemness characteristics of CSCs. TRF2 interacts with REST, KLF4 and other proteins (such asOct4 and Sox2) to increase the activity of tumor cell stemness-related transcription factors, promote tumor stem cell division and proliferation, drug resistance, EMT, invasion and metastasis, which have a major effect on tumor prognosis $(150,154,156,157)$. With the proliferation of tumor cells and the continuous development of the tumor, via the effect of angiogenesis-related factors or receptors, such as VEGF-A and PDGFR $\beta$, TRF2 can promote the formation of nourishing tumor blood vessels, which facilitates the nutrient uptake and metabolism of tumor cells, further enhancing tumor development and contributing to a poor prognosis $(7,136,137)$.

Therefore, the targeted treatment of TRF2 is important and has potential. Inhibition of TRF2 disrupts several pathways in which tumor cells depend for survival: It improves the immunosuppressive tumor microenvironment, promotes tumor cell apoptosis and CSC differentiation, inhibits the activity of telomerase and the ALT mechanism, and enhances the sensitivity of cancer cells to radiotherapy and chemotherapy $(157,160-164,166)$. Under the action of the aforementioned multiple anticancer factors, it is difficult for tumor cells to continue to proliferate or survive; therefore, the efficiency of tumor treatment is increased. After TRF2 expression level is knocked down, telomerase and ALT functions are also simultaneously inhibited, and the transcriptional activity of CSC stemness-related factors is blocked, which is conducive to the differentiation of CSCs and the loss of immortalization ability $(102,103,112,113,150)$. This can effectively inhibit the accumulation of malignant cell mutant genes in vivo, reduce the invasion and metastasis of tumor cells under the stress of treatment, and effectively remove mutated cells. However, with respect to safety, TRF2-targeted treatment may cause senescence and apoptosis of normal cells. Furthermore, specific adverse reactions require further evaluation. The specific targeting of tumor cell TRF2 is an issue, which requires resolving in TRF2 treatment research; however, the therapeutic prospects of this new target are worthy of further investigation.

\section{Acknowledgements}

Not applicable.

\section{Funding}

No funding was received.

\section{Availability of data and materials}

Not applicable.

\section{Author's contributions}

Both authors (ZW and XW) made substantial contributions to the collection, sorting, image processing, editing, writing, proofreading and revision of the manuscript, and approved the final version. Data sharing is not applicable. 


\section{Ethics approval and consent to participate}

Not applicable.

\section{Patient consent for publication}

Not applicable.

\section{Competing interests}

The authors declare that they have no competing interests.

\section{References}

1. Martincorena I, Fowler JC, Wabik A, Lawson ARJ, Abascal F Hall MWJ, Cagan A, Murai K, Mahbubani K, Stratton MR, et al: Somatic mutant clones colonize the human esophagus with age. Science 362: 911-917, 2018.

2. Yokoyama A, Kakiuchi N, Yoshizato T, Nannya Y, Suzuki H, Takeuchi Y, Shiozawa Y, Sato Y, Aoki K, Kim SK, et al: Age-related remodelling of oesophageal epithelia by mutated cancer drivers. Nature 565: 312-317, 2019.

3. Goerttler K, Loehrke H, Schweizer J and Hesse B: Two-stage skin carcinogenesis by systemic initiation of pregnant mice with 7,12-dimethylbenz(a)anthracene during gestation days 6-20 and postnatal promotion of the $\mathrm{F} 1$-generation with the phorbol ester 12-tetradecanoylphorbol-13-acetate. J Cancer Res Clin Oncol 98 : 267-275, 1980.

4. Goerttler K, Loehrke H, Hesse B, Milz A and Schweizer J Diaplacental initiation of NMRI mice with 7,12-dimethylbenz[a] anthracene during gestation days 6-20 and postnatal treatment of the F1-generation with the phorbol ester 12-O-tetradecanoylphorbol-13-acetate: Tumor incidence in organs other than the skin. Carcinogenesis 2: 1087-1094, 1981.

5. Fairall L, Chapman L, Moss H, de Lange T and Rhodes D Structure of the TRFH dimerization domain of the human telomeric proteins TRF1 and TRF2. Mol Cell 8: 351-361, 2001.

6. Mondello C, Smirnova A and Giulotto E: Gene amplification, radiation sensitivity and DNA double-strand breaks. Mutat Res 704: 29-37, 2010

7. El Maï M, Wagner KD, Michiels JF, Ambrosetti D, Borderie A, Destree S, Renault V, Djerbi N, Giraud-Panis MJ, Gilson E and Wagner N: The telomeric protein TRF2 regulates angiogenesis by binding and activating the PDGFR $\beta$ promoter. Cell Rep 9 . 1047-1060, 2014.

8. Biroccio A, Cherfils-Vicini J, Augereau A, Pinte S, Bauwens S, Ye J, Simonet T, Horard B, Jamet K, Cervera L, et al: TRF2 inhibits a cell-extrinsic pathway through which natural killer cells eliminate cancer cells. Nat Cell Biol 15: 818-828, 2013.

9. van Steensel B, Smogorzewska A and de Lange T: TRF2 protects human telomeres from end-to-end fusions. Cell 92: 401-413, 1998

10. de Lange T: Shelterin: The protein complex that shapes and safeguards human telomeres. Genes Dev 19: 2100-2110, 2005.

11. Smith EM, Pendlebury DF and Nandakumar J: Structural biology of telomeres and telomerase. Cell Mol Life Sci 77: 61-79, 2020.

12. Deng Z, Norseen J, Wiedmer A, Riethman H and Lieberman PM: TERRA RNA binding to TRF2 facilitates heterochromatin formation and ORC recruitment at telomeres. Mol Cell 35: 403-413, 2009

13. Necasová I, Janoušková E, Klumpler T and Hofr C: Basic domain of telomere guardian TRF2 reduces D-loop unwinding whereas Rap1 restores it. Nucleic Acids Res 45: 12170-12180, 2017.

14. O'Connor MS, Safari A, Xin H, Liu D and Songyang Z: A critical role for TPP1 and TIN2 interaction in high-order telomeric complex assembly. Proc Natl Acad Sci USA 103: 11874-11879, 2006.

15. Xin H, Liu D, Wan M, Safari A, Kim H, Sun W, O'Connor MS and Songyang Z: TPP1 is a homologue of ciliate TEBP-beta and interacts with POT1 to recruit telomerase. Nature 445: 559-562, 2007.

16. van Overbeek $M$ and de Lange T: Apollo, an Artemis-related nuclease, interacts with TRF2 and protects human telomeres in S phase. Curr Biol 16: 1295-1302, 2006.

17. Lenain C, Bauwens S, Amiard S, Brunori M, Giraud-Panis MJ and Gilson E: The Apollo 5'exonuclease functions together with TRF2 to protect telomeres from DNA repair. Curr Biol 16: $1303-1310,2006$.
18. Kim H, Lee OH, Xin H, Chen LY, Qin J, Chae HK, Lin SY, Safari A, Liu D and Songyang Z: TRF2 functions as a protein hub and regulates telomere maintenance by recognizing specific peptide motifs. Nat Struct Mol Biol 16: 372-379, 2009.

19. Benarroch-Popivker D, Pisano S, Mendez-Bermudez A, Lototska L, Kaur P, Bauwens S, Djerbi N, Latrick CM, Fraisier V, Pei B, et al: TRF2-mediated control of telomere DNA topology as a mechanism for chromosome-end protection. Mol Cell 61: 274-286, 2016.

20. Giraud-Panis MJ, Pisano S, Benarroch-Popivker D, Pei B Le Du MH and Gilson E: One identity or more for telomeres? Front Oncol 3: 48, 2013.

21. Broccoli D, Smogorzewska A, Chong L and de Lange T: Human telomeres contain two distinct Myb-related proteins, TRF1 and TRF2. Nat Genet 17: 231-235, 1997.

22. Baker AM, Fu Q, Hayward W, Lindsay SM and Fletcher TM: The $\mathrm{Myb} / \mathrm{SANT}$ domain of the telomere-binding protein TRF2 alters chromatin structure. Nucleic Acids Res 37: 5019-5031, 2009.

23. Bilaud T, Brun C, Ancelin K, Koering CE, Laroche T and Gilson E: Telomeric localization of TRF2, a novel human telobox protein. Nat Genet 17: 236-239, 1997.

24. Denchi EL and de Lange T: Protection of telomeres through independent control of ATM and ATR by TRF2 and POT1. Nature 448: 1068-1071, 2007.

25. Gilson E and Géli V: How telomeres are replicated. Nat Rev Mol Cell Biol 8: 825-838, 2007.

26. Ye J, Lenain C, Bauwens S, Rizzo A, Saint-Léger A, Poulet A, Benarroch D, Magdinier F, Morere J, Amiard S, et al: TRF2 and apollo cooperate with topoisomerase 2 alpha to protect human telomeres from replicative damage. Cell 142: 230-242, 2010.

27. Greider CW: Telomeres do D-loop-T-loop. Cell 97: 419-422, 1999.

28. Griffith JD, Comeau L, Rosenfield S, Stansel RM, Bianchi A, Moss $\mathrm{H}$ and de Lange T: Mammalian telomeres end in a large duplex loop. Cell 97: 503-514, 1999.

29. Timashev LA and De Lange T: Characterization of t-loop formation by TRF2. Nucleus 11: 164-177, 2020.

30. Feuerhahn S, Chen LY, Luke B and Porro A: No DDRama at chromosome ends: TRF2 takes centre stage. Trends Biochem Sci 40: 275-285, 2015.

31. Schmutz I, Timashev L, Xie W, Patel DJ and de Lange T: TRF2 binds branched DNA to safeguard telomere integrity. Nat Struct Mol Biol 24: 734-742, 2017.

32. Sarek G, Kotsantis P, Ruis P, Van Ly D, Margalef P, Borel V, Zheng XF, Flynn HR, Snijders AP, Chowdhury D, et al: CDK phosphorylation of TRF2 controls t-loop dynamics during the cell cycle. Nature 575: 523-527, 2019.

33. Sarek G, Vannier JB, Panier S, Petrini JHJ and Boulton SJ: TRF2 Recruits RTEL1 to Telomeres in S Phase to Promote T-Loop Unwinding. Mol Cell 61: 788-789, 2016.

34. Bower BD and Griffith JD: TRF1 and TRF2 differentially modulate Rad51-mediated telomeric and nontelomeric displacement loop formation in vitro. Biochemistry 53: 5485-5495, 2014.

35. d'Adda di Fagagna F, Reaper PM, Clay-Farrace L, Fiegler H, Carr P, Von Zglinicki T, Saretzki G, Carter NP and Jackson SP: A DNA damage checkpoint response in telomere-initiated senescence. Nature 426: 194-198, 2003.

36. Takai H, Smogorzewska A and de Lange T: DNA damage foci at dysfunctional telomeres. Curr Biol 13: 1549-1556, 2003.

37. Okamoto K, Bartocci C, Ouzounov I, Diedrich JK, Yates JR III and Denchi EL: A two-step mechanism for TRF2-mediated chromosome-end protection. Nature 494: 502-505, 2013.

38. Frescas D and de Lange T: TRF2-tethered TIN2 can mediate telomere protection by TPP1/POT1. Mol Cell Biol 34: 1349-1362, 2014.

39. Takai KK, Kibe T, Donigian JR, Frescas D and de Lange T: Telomere protection by TPP1/POT1 requires tethering to TIN2. Mol Cell 67: 162, 2017.

40. Fuchs E: The tortoise and the hair: Slow-cycling cells in the stem cell race. Cell 137: 811-819, 2009.

41. Opresko PL, von Kobbe C, Laine JP, Harrigan J, Hickson ID and Bohr VA: Telomere-binding protein TRF2 binds to and stimulates the Werner and Bloom syndrome helicases. J Biol Chem 277: 41110-41119, 2002.

42. Stavropoulos DJ, Bradshaw PS, Li X, Pasic I, Truong K, Ikura M, Ungrin M and Meyn MS: The Bloom syndrome helicase BLM interacts with TRF2 in ALT cells and promotes telomeric DNA synthesis. Hum Mol Genet 11: 3135-3144, 2002.

43. Rothkamm K, Krüger I, Thompson LH and Löbrich M: Pathways of DNA double-strand break repair during the mammalian cell cycle. Mol Cell Biol 23: 5706-5715, 2003. 
44. Mladenov E and Iliakis G: Induction and repair of DNA double strand breaks: The increasing spectrum of non-homologous end joining pathways. Mutat Res 711: 61-72, 2011.

45. Ribes-Zamora A, Indiviglio SM, Mihalek I, Williams CL and Bertuch AA: TRF2 interaction with Ku heterotetramerization interface gives insight into c-NHEJ prevention at human telomeres. Cell Rep 5: 194-206, 2013.

46. Dimitrova N, Chen YC, Spector DL and de Lange T: 53BP1 promotes non-homologous end joining of telomeres by increasing chromatin mobility. Nature 456: 524-528, 2008

47. Mirman Z, Lottersberger F, Takai H, Kibe T, Gong Y, Takai K, Bianchi A, Zimmermann M, Durocher D and de Lange T: 53BP1-RIF1-shieldin counteracts DSB resection through CSTand Pol $\alpha$-dependent fill-in. Nature 560: 112-116, 2018

48. Timashev LA, Babcock H, Zhuang X and de Lange T: The DDR at telomeres lacking intact shelterin does not require substantial chromatin decompaction. Genes Dev 31: 578-589, 2017.

49. Blasco MA: Telomeres and human disease: Ageing, cancer and beyond. Nat Rev Genet 6: 611-622, 2005.

50. Sfeir A and de Lange T: Removal of shelterin reveals the telomere end-protection problem. Science 336: 593-597, 2012.

51. Celli GB, Denchi EL and de Lange T: Ku70 stimulates fusion of dysfunctional telomeres yet protects chromosome ends from homologous recombination. Nat Cell Biol 8: 885-890, 2006.

52. Kibe T, Osawa GA, Keegan CE and de Lange T: Telomere protection by TPP1 is mediated by POT1a and POT1b. Mol Cell Biol 30: 1059-1066, 2010

53. Shamanna RA, Lu H, de Freitas JK, Tian J, Croteau DL and Bohr VA: WRN regulates pathway choice between classical and alternative non-homologous end joining. Nat Commun 7: 13785, 2016.

54. Fallet E, Jolivet P, Soudet J, Lisby M, Gilson E and Teixeira MT: Length-dependent processing of telomeres in the absence of telomerase. Nucleic Acids Res 42: 3648-3665, 2014

55. Wu L, Multani AS, He H, Cosme-Blanco W, Deng Y, Deng JM, Bachilo O, Pathak S, Tahara H, Bailey SM, et al: Pot1 deficiency initiates DNA damage checkpoint activation and aberrant homologous recombination at telomeres. Cell 126: 49-62, 2006.

56. Rai R, Chen Y, Lei M and Chang S: TRF2-RAP1 is required to protect telomeres from engaging in homologous recombination-mediated deletions and fusions. Nat Commun 7: 10881, 2016.

57. González-Prieto R, Cuijpers SA, Luijsterburg MS, van Attikum $\mathrm{H}$ and Vertegaal AC: SUMOylation and PARylation cooperate to recruit and stabilize SLX4 at DNA damage sites. EMBO Rep 16: 512-519, 2015

58. Capper R, Britt-Compton B, Tankimanova M, Rowson J, Letsolo B, Man S, Haughton M and Baird DM: The nature of telomere fusion and a definition of the critical telomere length in human cells. Genes Dev 21: 2495-2508, 2007.

59. Karlseder J, Smogorzewska A and de Lange T: Senescence induced by altered telomere state, not telomere loss. Science 295 : 2446-2449, 2002.

60. Smogorzewska A, van Steensel B, Bianchi A, Oelmann S, Schaefer MR, Schnapp G and de Lange T: Control of human telomere length by TRF1 and TRF2. Mol Cell Biol 20: 1659-1668, 2000.

61. Muñoz P, Blanco R and Blasco MA: Role of the TRF2 telomeric protein in cancer and ageing. Cell Cycle 5: 718-721, 2006.

62. Saint-Léger A, Koelblen M, Civitelli L, Bah A, Djerbi N, Giraud-Panis MJ, Londoño-Vallejo A, Ascenzioni $F$ and Gilson E: The basic N-terminal domain of TRF2 limits recombination endonuclease action at human telomeres. Cell Cycle 13 2469-2474, 2014

63. Wilson JS, Tejera AM, Castor D, Toth R, Blasco MA and Rouse J: Localization-dependent and -independent roles of SLX4 in regulating telomeres. Cell Rep 4: 853-860, 2013.

64. Wu Y, Zacal NJ, Rainbow AJ and Zhu XD: XPF with mutations in its conserved nuclease domain is defective in DNA repair but functions in TRF2-mediated telomere shortening. DNA Repair (Amst) 6: 157-166, 2007.

65. Wu Y, Mitchell TR and Zhu XD: Human XPF controls TRF2 and telomere length maintenance through distinctive mechanisms. Mech Ageing Dev 129: 602-610, 2008.

66. Menendez JA, Rubio MA, Campisi J and Lupu R: Heregulin, a new regulator of telomere length in human cells. Oncotarget 6 : 39422-39436, 2015.

67. Menendez JA, Benboudjema L, Vellon L, Rubio MA, Espinoza I, Campisi J and Lupu R: Heregulin, a new interactor of the telosome/shelterin complex in human telomeres. Oncotarget 6 : 39408-39421, 2015.
68. Baur JA, Zou Y, Shay JW and Wright WE: Telomere position effect in human cells. Science 292: 2075-2077, 2001

69. Kim W, Ludlow AT, Min J, Robin JD, Stadler G, Mender I, Lai TP, Zhang N, Wright WE and Shay JW: Regulation of the human telomerase gene TERT by telomere position effect-over long distances (TPE-OLD): Implications for aging and cancer. PLoS Biol 14: e2000016, 2016

70. Mukherjee AK, Sharma S, Bagri S, Kutum R, Kumar P, Hussain A, Singh P, Saha D, Kar A, Dash D and Chowdhury S: Telomere repeat-binding factor 2 binds extensively to extra-telomeric G-quadruplexes and regulates the epigenetic status of several gene promoters. J Biol Chem 294: 17709-17722, 2019.

71. Bradshaw PS, Stavropoulos DJ and Meyn MS: Human telomeric protein TRF2 associates with genomic double-strand breaks as an early response to DNA damage. Nat Genet 37: 193-197, 2005.

72. Hussain T, Saha D, Purohit G, Kar A, Kishore Mukherjee A, Sharma S, Sengupta S, Dhapola P, Maji B, Vedagopuram S, et al: Transcription regulation of CDKN1A (p21/CIP1/WAF1) by TRF2 is epigenetically controlled through the REST repressor complex. Sci Rep 7: 11541, 2017

73. Purohit G, Mukherjee AK, Sharma S and Chowdhury S: Extratelomeric binding of the telomere binding protein TRF2 at the PCGF3 promoter is G-Quadruplex Motif-dependent. Biochemistry 57: 2317-2324, 2018.

74. Williamson JR, Raghuraman MK and Cech TR: Monovalent cation-induced structure of telomeric DNA: The G-quartet model. Cell 59: 871-880, 1989.

75. Phan AT: Human telomeric G-quadruplex: Structures of DNA and RNA sequences. FEBS J 277: 1107-1117, 2010.

76. Muniyappa K and Kironmai KM: Telomere structure, replication and length maintenance. Crit Rev Biochem Mol Biol 33: 297-336, 1998.

77. Luu KN, Phan AT, Kuryavyi V, Lacroix L and Patel DJ: Structure of the human telomere in K+ solution: An intramolecular $(3+1)$ G-quadruplex scaffold. J Am Chem Soc 128: 9963-9970, 2006.

78. Brázda V, Hároníková L, Liao JC and Fojta M: DNA and RNA quadruplex-binding proteins. Int J Mol Sci 15: 17493-17517, 2014.

79. Pedroso IM, Hayward W and Fletcher TM: The effect of the TRF2 N-terminal and TRFH regions on telomeric G-quadruplex structures. Nucleic Acids Res 37: 1541-1554, 2009

80. Rawal P, Kummarasetti VB, Ravindran J, Kumar N, Halder K, Sharma R, Mukerji M, Das SK and Chowdhury S: Genome-wide prediction of G4 DNA as regulatory motifs: Role in Escherichia coli global regulation. Genome Res 16: 644-655, 2006

81. Sengupta A,Roy SS and Chowdhury S: Non-duplex G-Quadruplex DNA Structure: A developing story from predicted sequences to DNA structure-dependent epigenetics and beyond. Acc Chem Res 54: 46-56, 2021.

82. Killela PJ, Pirozzi CJ, Healy P, Reitman ZJ, Lipp E, Rasheed BA, Yang R, Diplas BH, Wang Z, Greer PK, et al: Mutations in IDH1, IDH2, and in the TERT promoter define clinically distinct subgroups of adult malignant gliomas. Oncotarget 5: 1515-1525, 2014.

83. Heidenreich B, Nagore E, Rachakonda PS, Garcia-Casado Z, Requena C, Traves V, Becker J, Soufir N, Hemminki K and Kumar R: Telomerase reverse transcriptase promoter mutations in primary cutaneous melanoma. Nat Commun 5: 3401, 2014.

84. Pinyol R, Tovar V and Llovet JM: TERT promoter mutations: Gatekeeper and driver of hepatocellular carcinoma. J Hepatol 61: 685-687, 2014

85. Rachakonda PS, Hosen I, de Verdier PJ, Fallah M, Heidenreich B, Ryk C, Wiklund NP, Steineck G, Schadendorf D, Hemminki K and Kumar R: TERT promoter mutations in bladder cancer affect patient survival and disease recurrence through modification by a common polymorphism. Proc Natl Acad Sci USA 110: 17426-17431, 2013.

86. Thakur RK, Kumar P, Halder K, Verma A, Kar A, Parent JL, Basundra R, Kumar A and Chowdhury S: Metastases suppressor NM23-H2 interaction with G-quadruplex DNA within c-MYC promoter nuclease hypersensitive element induces c-MYC expression. Nucleic Acids Res 37: 172-183, 2009.

87. Paramasivam M, Membrino A, Cogoi S, Fukuda H, Nakagama $\mathrm{H}$ and Xodo LE: Protein hnRNP A1 and its derivative Upl unfold quadruplex DNA in the human KRAS promoter: Implications for transcription. Nucleic Acids Res 37: 2841-2853, 2009.

88. Cogoi S, Paramasivam M, Membrino A, Yokoyama KK and Xodo LE: The KRAS promoter responds to Myc-associated zinc finger and poly(ADP-ribose) polymerase 1 proteins, which recognize a critical quadruplex-forming GA-element. J Biol Chem 285: 22003-22016, 2010. 
89. Yadav VK, Abraham JK, Mani P,Kulshrestha R and Chowdhury S QuadBase: Genome-wide database of G4 DNA-occurrence and conservation in human, chimpanzee, mouse and rat promoters and 146 microbes. Nucleic Acids Res 36: D381-D385, 2008.

90. Mukherjee AK, Sharma S, Sengupta S, Saha D, Kumar P, Hussain T, Srivastava V, Roy SD, Shay JW and Chowdhury S: Telomere length-dependent transcription and epigenetic modifications in promoters remote from telomere ends. PLoS Genet 14: e1007782, 2018

91. Shay JW and Wright WE: Telomeres and telomerase: Three decades of progress. Nat Rev Genet 20: 299-309, 2019.

92. Rajagopalan $\mathrm{H}$ and Lengauer C: CIN-ful cancers. Cancer Chemother Pharmacol 54 (Suppl 1): S65-S68, 2004.

93. Tlsty TD: Genomic instability and its role in neoplasia. Curr Top Microbiol Immunol 221: 37-46, 1997.

94. Lengauer C, Kinzler KW and Vogelstein B. Genetic instabilities in human cancers. Nature 396: 643-649, 1998.

95. Palm W and de Lange T: How shelterin protects mammalian telomeres. Annu Rev Genet 42: 301-334, 2008.

96. Wright WE, Pereira-Smith OM and Shay JW: Reversible cellular senescence: Implications for immortalization of normal human diploid fibroblasts. Mol Cell Biol 9: 3088-3092, 1989.

97. O'Hagan RC, Chang S, Maser RS, Mohan R, Artandi SE, Chin L and DePinho RA: Telomere dysfunction provokes regional amplification and deletion in cancer genomes. Cancer Cell 2: 149-155, 2002.

98. Fumagalli M, Rossiello F, Clerici M, Barozzi S, Cittaro D, Kaplunov JM, Bucci G, Dobreva M, Matti V, Beausejour CM, et al: Telomeric DNA damage is irreparable and causes persistent DNA-damage-response activation. Nat Cell Biol 14: 355-365, 2012

99. Feldser DM and Greider CW: Short telomeres limit tumor progression in vivo by inducing senescence. Cancer Cell 11: 461-469, 2007.

100. Counter CM, Avilion AA, LeFeuvre CE, Stewart NG, Greider CW, Harley CB and Bacchetti S: Telomere shortening associated with chromosome instability is arrested in immortal cells which express telomerase activity. EMBO J 11: 1921-1929, 1992.

101. Hayashi MT, Cesare AJ, Rivera T and Karlseder J: Cell death during crisis is mediated by mitotic telomere deprotection. Nature 522: 492-496, 2015.

102. Sabatier L, Ricoul M, Pottier G and Murnane JP: The loss of a single telomere can result in instability of multiple chromosomes in a human tumor cell line. Mol Cancer Res 3: 139-150, 2005

103. Bailey SM and Murnane JP: Telomeres, chromosome instability and cancer. Nucleic Acids Res 34: 2408-2417, 2006.

104. Maciejowski J and de Lange T: Telomeres in cancer: Tumour suppression and genome instability. Nat Rev Mol Cell Biol 18 $175-186,2017$

105. Martínez P and Blasco MA: Telomere-driven diseases and telomere-targeting therapies. J Cell Biol 216: 875-887, 2017.

106. Murnane JP and Sabatier L: Chromosome rearrangements resulting from telomere dysfunction and their role in cancer. Bioessays 26: 1164-1174, 2004.

107. Giraud-Panis MJ, Pisano S, Poulet A, Le Du MH and Gilson E: Structural identity of telomeric complexes. FEBS Lett 584 3785-3799, 2010.

108. Salhab M, Jiang WG, Newbold RF and Mokbel K: The expression of gene transcripts of telomere-associated genes in human breast cancer: Correlation with clinico-pathological parameters and clinical outcome. Breast Cancer Res Treat 109: 35-46, 2008.

109. Pascua I, Fernández-Marcelo T, Sánchez-Pernaute A, de Juan C, Head J, Torres-García AJ and Iniesta P: Prognostic value of telomere function in gastric cancers with and without microsatellite instability. Eur J Gastroenterol Hepatol 27: 162-169, 2015.

110. Yamada K, Yagihashi A, Yamada M, Asanuma K, Moriai R, Kobayashi D, Tsuji N and Watanabe N: Decreased gene expression for telomeric-repeat binding factors and TIN2 in malignant hematopoietic cells. Anticancer Res 22: 1315-1320, 2002.

111. Su CH, Cheng C, Tzeng TY, Lin IH and Hsu MT: An H2A Histone Isotype, $\mathrm{H} 2 \mathrm{ac}$, associates with telomere and maintains telomere integrity. PLoS One 11: e0156378, 2016

112. Bojovic B, Ho HY, Wu J and Crowe DL: Stem cell expansion during carcinogenesis in stem cell-depleted conditional telomeric repeat factor 2 null mutant mice. Oncogene 32: 5156-5166, 2013.

113. Lagunas AM, Wu J and Crowe DL: Telomere DNA damage signaling regulates cancer stem cell evolution, epithelial mesenchymal transition, and metastasis. Oncotarget 8: 80139-80155, 2017.

114. Rossi DJ, Jamieson CH and Weissman IL: Stems cells and the pathways to aging and cancer. Cell 132: 681-696, 2008
115. Singh A and Settleman J: EMT, cancer stem cells and drug resistance: An emerging axis of evil in the war on cancer. Oncogene 29: 4741-4751, 2010.

116. Härle-Bachor C and Boukamp P: Telomerase activity in the regenerative basal layer of the epidermis inhuman skin and in immortal and carcinoma-derived skin keratinocytes. Proc Natl Acad Sci USA 93: 6476-6481, 1996

117. González-Suárez E, Samper E, Ramírez A, Flores JM, Martín-Caballero J, Jorcano JL and Blasco MA: Increased epidermal tumors and increased skin wound healing in transgenic mice overexpressing the catalytic subunit of telomerase, mTERT, in basal keratinocytes. EMBO J 20: 2619-2630, 2001.

118. Blanco R, Muñoz P, Flores JM, Klatt P and Blasco MA Telomerase abrogation dramatically accelerates TRF2-induced epithelial carcinogenesis. Genes Dev 21: 206-220, 2007.

119. Matsutani N, Yokozaki H, Tahara E, Tahara H, Kuniyasu H, Haruma K, Chayama K, Yasui W and Tahara E: Expression of telomeric repeat binding factor 1 and 2 and TRF1-interacting nuclear protein 2 in human gastric carcinomas. Int J Oncol 19: 507-512, 2001

120. Oh BK, Kim YJ, Park C and Park YN: Up-regulation of telomere-binding proteins, TRF1, TRF2, and TIN2 is related to telomere shortening during human multistep hepatocarcinogenesis. Am J Pathol 166: 73-80, 2005

121. Xu L and Blackburn EH: Human cancer cells harbor T-stumps, a distinct class of extremely short telomeres. Mol Cell 28: 315-327, 2007.

122. Muñoz P, Blanco R, Flores JM and Blasco MA: XPF nuclease-dependent telomere loss and increased DNA damage in mice overexpressing TRF2 result in premature aging and cancer. Nat Genet 37: 1063-1071, 2005.

123. Nera B, Huang HS, Lai T and Xu L: Elevated levels of TRF2 induce telomeric ultrafine anaphase bridges and rapid telomere deletions. Nat Commun 6: 10132, 2015.

124. Rai R, Zheng H, He H, Luo Y, Multani A, Carpenter PB and Chang S: The function of classical and alternative non-homologous end-joining pathways in the fusion of dysfunctional telomeres. EMBO J 29: 2598-2610, 2010.

125. Dong W, Shen R, Wang Q, Gao Y, Qi X, Jiang H, Yao J, Lin X, Wu Y and Wang L: Sp1 upregulates expression of TRF2 and TRF2 inhibition reduces tumorigenesis in human colorectal carcinoma cells. Cancer Biol Ther 8: 2166-2174, 2009.

126. Raynaud CM, Jang SJ, Nuciforo P, Lantuejoul S, Brambilla E, Mounier N, Olaussen KA, André F, Morat L, Sabatier L and Soria JC: Telomere shortening is correlated with the DNA damage response and telomeric protein down-regulation in colorectal preneoplastic lesions. Ann Oncol 19: 1875-1881, 2008.

127. Brummelkamp TR, Bernards R and Agami R: A system for stable expression of short interfering RNAs in mammalian cells. Science 296: 550-553, 2002.

128. Gartel AL, Goufman E, Najmabadi F and Tyner AL: Sp1 and Sp3 activate $\mathrm{p} 21$ (WAF1/CIP1) gene transcription in the Caco-2 colon adenocarcinoma cell line. Oncogene 19: 5182-5188, 2000.

129. Takami Y, Russell MB, Gao C, Mi Z, Guo H, Mantyh CR and Kuo PC: Sp1 regulates osteopontin expression in SW480 human colon adenocarcinoma cells. Surgery 142: 163-169, 2007.

130.Zhu GH, Lenzi M and Schwartz EL: The Sp1 transcription factor contributes to the tumor necrosis factor-induced expression of the angiogenic factor thymidine phosphorylase in human colon carcinoma cells. Oncogene 21: 8477-8485, 2002.

131. Diala I, Wagner N, Magdinier F, Shkreli M, Sirakov M, Bauwens S, Schluth-Bolard C, Simonet T, Renault VM, Ye J, et al: Telomere protection and TRF2 expression are enhanced by the canonical Wnt signalling pathway. EMBO Rep 14: 356-363, 2013

132. Wu S, Ge Y, Li X, Yang Y, Zhou H, Lin K, Zhang Z and Zhao Y: BRM-SWI/SNF chromatin remodeling complex enables functional telomeres by promoting co-expression of TRF2 and TRF1. PLoS Genet 16: e1008799, 2020.

133. Dong W, Wang L, Chen X, Sun P and Wu Y: Upregulation and $\mathrm{CpG}$ island hypomethylation of the TRF2 gene in human gastric cancer. Dig Dis Sci 55: 997-1003, 2010.

134. Luo Z, Feng X, Wang H, Xu W, Zhao Y, Ma W, Jiang S, Liu D, Huang J and Songyang Z: Mir-23a induces telomere dysfunction and cellular senescence by inhibiting TRF2 expression. Aging Cell 14: 391-399, 2015.

135. Dinami R, Ercolani C, Petti E, Piazza S, Ciani Y, Sestito R, Sacconi A, Biagioni F, le Sage C, Agami R, et al: miR-155 drives telomere fragility in human breast cancer by targeting TRF1. Cancer Res 74: 4145-4156, 2014 
136. Dinami R, Porru M, Amoreo CA, Sperduti I, Mottolese M, Buglioni S, Marinelli D, Maugeri-Saccà M, Sacconi A, Blandino G, et al: TRF2 and VEGF-A: An unknown relationship with prognostic impact on survival of colorectal cancer patients. J Exp Clin Cancer Res 39: 111, 2020.

137. Zizza P, Dinami R, Porru M, Cingolani C, Salvati E, Rizzo A D'Angelo C, Petti E, Amoreo CA, Mottolese M, et al: TRF2 positively regulates SULF2 expression increasing VEGF-A release and activity in tumor microenvironment. Nucleic Acids Res 47: 3365-3382, 2019.

138. Gavert N and Ben-Ze'ev A: Beta-Catenin signaling in biological control and cancer. J Cell Biochem 102: 820-828, 2007.

139. Dhillon AS, Hagan S, Rath O and Kolch W: MAP kinase signalling pathways in cancer. Oncogene 26: 3279-3290, 2007.

140. Jones SM and Kazlauskas A: Growth factor-dependent signaling and cell cycle progression. FEBS Lett 490: 110-116, 2001.

141. Roberts EC, Shapiro PS, Nahreini TS, Pages G, Pouyssegur J and Ahn NG: Distinct cell cycle timing requirements for extracellular signal-regulated kinase and phosphoinositide 3-kinase signaling pathways in somatic cell mitosis. Mol Cell Biol 22: 7226-7241, 2002 .

142. Nijjar T, Bassett E, Garbe J, Takenaka Y, Stampfer MR, Gilley D and Yaswen P: Accumulation and altered localization of telomere-associated protein TRF2 in immortally transformed and tumor-derived human breast cells. Oncogene 24: 3369-3376, 2005.

143. Picco V, Coste I, Giraud-Panis MJ, Renno T, Gilson E and Pagès G: ERK1/2/MAPK pathway-dependent regulation of the telomeric factor TRF2. Oncotarget 7: 46615-46627, 2016.

144. Shukla S, Kanwal R, Shankar E, Datt M, Chance MR, Fu P, MacLennan GT and Gupta S: Apigenin blocks IKK $\alpha$ activation and suppresses prostate cancer progression. Oncotarget 6 : 31216-31232, 2015.

145. Li T, Wong VK, Jiang ZH, Jiang SP, Liu Y, Wang TY, Yao XJ, $\mathrm{Su}$ XH, Yan FG, Liu J, et al: Mutation of cysteine 46 in IKK-beta increases inflammatory responses. Oncotarget 6: 31805-31819, 2015.

146. An J, Wu M, Xin X, Lin Z, Li X, Zheng Q, Gui X, Li T, Pu H, $\mathrm{Li} \mathrm{H}$ and $\mathrm{Lu} \mathrm{D}$ : Inflammatory related gene IKK $\alpha, \operatorname{IKK} \beta, \operatorname{IKK} \gamma$ cooperates to determine liver cancer stem cells progression by altering telomere via heterochromatin protein 1-HOTAIR axis. Oncotarget 7: 50131-50149, 2016.

147. Baskar R, Dai J, Wenlong N, Yeo R and Yeoh KW: Biological response of cancer cells to radiation treatment. Front Mol Biosci 1: 24, 2014.

148. Saha A, Shree Padhi S, Roy S and Banerjee B: HCT116 colonospheres shows elevated expression of hTERT and $\beta$-catenin protein-a short report. J Stem Cells 9: 243-251, 2014.

149. Saha A, Roy S, Kar M, Roy S, Thakur S, Padhi S, Akhter Y and Banerjee B: Role of telomeric TRF2 in orosphere formation and CSC phenotype maintenance through efficient DNA repair pathway and its correlation with recurrence in OSCC. Stem Cell Rev Rep 14: 871-887, 2018.

150. Janoušková E, Nečasová I, Pavloušková J, Zimmermann $M$, Hluchý M, Marini V, Nováková M and Hofr C: Human Rap1 modulates TRF2 attraction to telomeric DNA. Nucleic Acids Res 43: 2691-2700, 2015

151. Anuja K, Chowdhury AR, Saha A, Roy S, Rath AK, Kar M and Banerjee B: Radiation-induced DNA damage response and resistance in colorectal cancer stem-like cells. Int J Radiat Biol 95: 667-679, 2019.

152. Osterwald S, Deeg KI, Chung I, Parisotto D, Wörz S, Rohr K, Erfle H and Rippe K: PML induces compaction, TRF2 depletion and DNA damage signaling at telomeres and promotes their alternative lengthening. J Cell Sci 128: 1887-1900, 2015.

153. Zhang P, Pazin MJ, Schwartz CM, Becker KG, Wersto RP, Dilley CM and Mattson MP: Nontelomeric TRF2-REST interaction modulates neuronal gene silencing and fate of tumor and stem cells. Curr Biol 18: 1489-1494, 2008.

154. Preusser M, de Ribaupierre S, Wöhrer A, Erridge SC, Hegi M, Weller M and Stupp R: Current concepts and management of glioblastoma. Ann Neurol 70: 9-21, 2011

155. Bao S, Wu Q, McLendon RE, Hao Y, Shi Q, Hjelmeland AB, Dewhirst MW, Bigner DD and Rich JN: Glioma stem cells promote radioresistance by preferential activation of the DNA damage response. Nature 444: 756-760, 2006.

156. Bai Y, Lathia JD, Zhang P,Flavahan W, Rich JN and Mattson MP: Molecular targeting of TRF2 suppresses the growth and tumorigenesis of glioblastoma stem cells. Glia 62: 1687-1698, 2014

157. Simonet T, Zaragosi LE, Philippe C, Lebrigand K, Schouteden C, Augereau A, Bauwens S, Ye J, Santagostino M, Giulotto E, et al: The human TTAGGG repeat factors 1 and 2 bind to a subset of interstitial telomeric sequences and satellite repeats. Cell Res 21: 1028-1038, 2011.
158. Cherfils-Vicini J,Iltis C, Cervera L, Pisano S, Croce O, Sadouni N, Győrffy B, Collet R, Renault VM, Rey-Millet M, et al: Cancer cells induce immune escape via glycocalyx changes controlled by the telomeric protein TRF2. EMBO J 38: e100012, 2019.

159. Talmadge JE and Gabrilovich DI: History of myeloid-derived suppressor cells. Nat Rev Cancer 13: 739-752, 2013.

160. Karlseder J, Broccoli D, Dai Y, Hardy S and de Lange T: p53and ATM-dependent apoptosis induced by telomeres lacking TRF2. Science 283: 1321-1325, 1999.

161. Pal D, Sharma U, Singh SK, Kakkar N and Prasad R: Over-expression of telomere binding factors (TRF1 \& TRF2) in renal cell carcinoma and their inhibition by using SiRNA induce apoptosis, reduce cell proliferation and migration in vitro. PLoS One 10: e0115651, 2015.

162. Bidzinska J, Baginski M and Skladanowski A: Novel anticancer strategy aimed at targeting shelterin complexes by the induction of structural changes in telomeric DNA: Hitting two birds with one stone. Curr Cancer Drug Targets 14: 201-216, 2014.

163. Horikawa I, Fujita K and Harris CC: p53 governs telomere regulation feedback too, via TRF2. Aging (Albany NY) 3: 26-32, 2011.

164. Yang X, Li Z, Yang L, Lei H, Yu H, Liao Z, Zhou F, Xie C and Zhou Y: Knockdown of telomeric repeat binding factor 2 enhances tumor radiosensitivity regardless of telomerase status. J Cancer Res Clin Oncol 141: 1545-1552, 2015.

165. Cabuy E, Newton C, Joksic G, Woodbine L, Koller B, Jeggo PA and Slijepcevic P: Accelerated telomere shortening and telomere abnormalities in radiosensitive cell lines. Radiat Res 164: 53-62, 2005.

166. Zhong YH, Liao ZK, Zhou FX, Xie CH, Xiao CY, Pan DF, Luo ZG, Liu SQ and Zhou YF: Telomere length inversely correlates with radiosensitivity in human carcinoma cells with the same tissue background. Biochem Biophys Res Commun 367: 84-89, 2008.

167. Orun O, Tiber PM and Serakinci N: Partial knockdown of TRF2 increase radiosensitivity of human mesenchymal stem cells. Int J Biol Macromol 90: 53-58, 2016.

168. Ning HB, Li JC, Liu ZG and Fan DM: DNA damage increases telomerase activity and mRNA expression of telomeric repeat binding factor 2 in gastric cancer cells. Available in: www.cnki.net. World Chin J Digest 14: 942-946, 2006

169. Ning HB, Wang YH, Zhang LF, et al: Reversal of multidrug resistance in gastric cancer cells by telomeric repeat binding factor 2 small interfering RNA. Available in: www.cnki.net. Chin J Diges 31: 481-483, 2011.

170. Benhamou Y, Picco V, Raybaud H, Sudaka A, Chamorey E, Brolih S, Monteverde M, Merlano M, Lo Nigro C, Ambrosetti D and Pagès G: Telomeric repeat-binding factor 2: A marker for survival and anti-EGFR efficacy in oral carcinoma. Oncotarget 7: 44236-44251, 2016.

171. Roy S, Roy S, Kar M, Thakur S, Akhter Y, Kumar A, Delogu F, Padhi S, Saha A and Banerjee B: p38 MAPK pathway and its interaction with TRF2 in cisplatin induced chemotherapeutic response in head and neck cancer. Oncogenesis 7: 53, 2018.

172. Apetoh L, Végran F, Ladoire S and Ghiringhelli F: Restoration of antitumor immunity through selective inhibition of myeloid derived suppressor cells by anticancer therapies. Curr Mol Med 11: 365-372, 2011.

173. Bruchard M, Mignot G, Derangère V, Chalmin F, Chevriaux A Végran F, Boireau W, Simon B, Ryffel B, Connat JL, et al: Chemotherapy-triggered cathepsin $\mathrm{B}$ release in myeloid-derived suppressor cells activates the Nlrp3 inflammasome and promotes tumor growth. Nat Med 19: 57-64, 2013.

174. Sevko A, Michels T, Vrohlings M, Umansky L, Beckhove P, Kato M, Shurin GV, Shurin MR and Umansky V: Antitumor effect of paclitaxel is mediated by inhibition of myeloid-derived suppressor cells and chronic inflammation in the spontaneous melanoma model. J Immunol 190: 2464-2471, 2013.

175. Wang M, Cao J, Zhu JY, Qiu J, Zhang Y, Shu B, Ou TM, Tan JH, Gu LQ, Huang ZS, et al: Curcusone C induces telomeric DNA-damage response in cancer cells through inhibition of telomeric repeat factor 2. Biochim Biophys Acta Proteins Proteom 1865: 1372-1382, 2017.

176. Jiao Y, Zhang W, Liu J, Ni W, Xu W, Jin J and Qian W: Telomere attrition and chromosome instability via downregulation of TRF2 contributes to arsenic trioxide-induced apoptosis of human T-Cell leukemia cell line molt-4 cells. Cancer Biol Ther 6: 1186-1192, 2007. 